Article

\title{
Numerical Investigation of SCR Mixer Design Optimization for Improved Performance
}

\author{
Ghazanfar Mehdi ${ }^{1, *}$, Song Zhou ${ }^{1, *}$, Yuanqing Zhu ${ }^{1}{ }^{\mathbb{D}}$, Ahmer Hussain Shah ${ }^{2}$ and \\ Kishore Chand ${ }^{3}$ \\ 1 College of Energy and Power Engineering, Harbin Engineering University, Harbin 150001, China; \\ zhuyuanqing@hrbeu.edu.cn \\ 2 Department of Textile Engineering, Balochistan University of Information Technology, \\ Engineering and Management Sciences, Quetta 87300, Pakistan; ahmer.shah@buitms.edu.pk \\ 3 College of Material Science and Chemical Engineering, Harbin Engineering University, Harbin 150001, \\ China; kishor.vallasai@gmail.com \\ * Correspondence: ghazanfarmehdi22@gmail.com (G.M.); songzhou@hrbeu.edu.cn (S.Z.); \\ Tel.: +86-130-3004-8065 (G.M.); +86-138-4506-3167 (S.Z.)
}

Received: 1 February 2019; Accepted: 18 March 2019; Published: 22 March 2019

\begin{abstract}
The continuous increase in the number of stringent exhaust emission legislations of marine Diesel engines had led to a decrease in $\mathrm{NO}_{x}$ emissions at the required level. Selective catalyst reduction (SCR) is the most prominent and mature technology used to reduce $\mathrm{NO}_{\mathrm{x}}$ emissions. However, to obtain maximum $\mathrm{NO}_{\mathrm{x}}$ removal with minimum ammonia slip remains a challenge. Therefore, new mixers are designed in order to obtain the maximum SCR efficiency. This paper reports performance parameters such as uniformity of velocity, ammonia uniformity distribution, and temperature distribution. Also, a numerical model is developed to investigate the interaction of urea droplet with exhaust gas and its effects by using line (LM) and swirl (SM) type mixers alone and in combination (LSM). The urea droplet residence time and its interaction in straight pipe are also investigated. Model calculations proved the improvement in velocity uniformity, distribution of ammonia uniformity, and temperature distribution for LSM. Prominent enhancement in the evaporation rate was also achieved by using LSM, which may be due to the breaking of urea droplets into droplets of smaller diameter. Therefore, the SCR system accomplished higher urea conversion efficiency by using LSM. Lastly, the ISO 8178 standard engine test cycle E3 was used to verify the simulation results. It has been observed that the average weighted value of $\mathrm{NO}_{\mathrm{x}}$ emission obtained at SCR outlet using LSM was $2.44 \mathrm{~g} / \mathrm{kWh}$, which strongly meets International Maritime Organization (IMO) Tier III $\mathrm{NO}_{\mathrm{x}}(3.4 \mathrm{~g} / \mathrm{kWh})$ emission regulations.
\end{abstract}

Keywords: selective catalyst reduction system; emission control; marine Diesel engine; urea; ammonia

\section{Introduction}

Environmental safety is one of the hottest research areas nowadays due to increased public awareness. To achieve this goal, efforts are continuously made to reduce pollution and develop green processes. Exhaust emissions from marine Diesel engine are responsible for producing severe environmental pollution, especially nitrogen oxide $\left(\mathrm{NO}_{\mathrm{x}}\right)$ emissions $[1,2]$. The automobile Diesel engine produces exhaust emissions species such as carbon monoxide, carbon dioxide, and hydrocarbon in abundance compared to $\mathrm{NO}_{\mathrm{x}}$. On the other hand, marine Diesel engine produces more detrimental $\mathrm{NO}_{x}$ emissions [3]. Hence, in order to reduce exhaust emissions from ships, many national and international organizations have promulgated regulations and also enforced strict requirements on 
$\mathrm{NO}_{x}$ emissions in Emission Control Areas [4]. In 2016, International Maritime organization (IMO) Tier III regulations on $\mathrm{NO}_{x}$ emissions have already been enforced in North America emission control areas, including the East and West Coast of USA and Caribbean. As reported, it will also be enforced in North Sea and Baltic Sea in future [5]. Both high pressure fuel injection and exhaust gas recirculation systems have potential to reduce $\mathrm{NO}_{\mathrm{x}}$ emissions, but due to poor engine performance results and continuous increase in engine emission legislations, more primitive and improved processes are needed to overcome the said issues [6]. The most convenient and easy option is the treatment of exhaust gas. Selective Catalyst Reduction (SCR) is technically mature, and is the most prominent after-treatment technology used to meet the latest $\mathrm{NO}_{\mathrm{x}}$ emission regulations due to its high $\mathrm{NO}_{\mathrm{x}}$ removal efficiency, cost-effectiveness, and good fuel economy [7]. However, challenges related with SCR system include improper mixture of urea water solution (UWS) with exhaust gas and ammonia leakage [8]. UWS (32.5\% urea) is injected into exhaust gas [9,10]. Urea decomposition occurs in three steps: firstly, water is evaporated from urea water solution; secondly, the urea pyrolysis reaction occurs, which results in the decomposition of urea into isocyanic acid ( $\mathrm{HNCO})$ and ammonia $\left(\mathrm{NH}_{3}\right)$; and lastly, hydrolysis of $\mathrm{HNCO}$ occurs which produces $\mathrm{NH}_{3}$ and $\mathrm{CO}_{2}$ [11,12]. Ammonia is used as a reducing agent and cannot be used directly due to poisonous nature, storing and handling difficulties [13]. It has been proved that $\mathrm{NO}_{\mathrm{x}}$ is mainly $90 \%$ composition of $\mathrm{NO}$ at the exhaust of the marine Diesel engine. The key reactions involved in SCR system are described as follows [14-17].
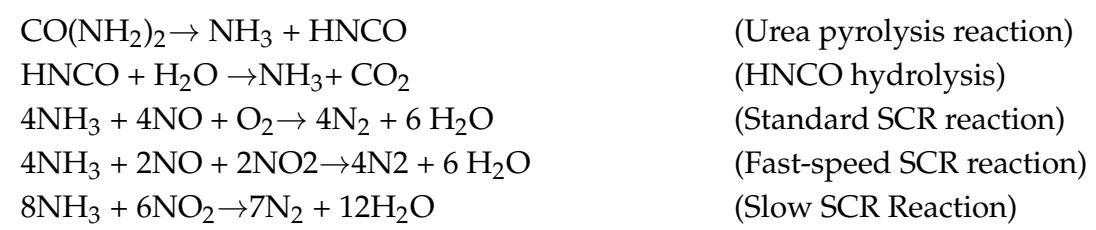

A static mixer is commonly adopted to generate uniform distribution of ammonia at the inlet of SCR catalyst [18]. CFD code (Fire 8.3, 2004) has been used to optimize the design of SCR system. The authors have done many studies about the decomposition and evaporation of urea water solution without using static mixer. Birkhold [19] studied the urea droplet's evaporation and decomposition at different temperatures of exhaust gas. Strom [20] studied the effects of turbulent velocity and different forces on distribution and movements of urea water droplet in the exhaust species. In addition, other authors have established various studies to evaluate the effect of static mixer on the SCR performance. Sivanandi Rajadurai [21] studied the distribution of ammonia by using wire mesh mixer. Zhang [22] investigated the uniformity index of ammonia by adopting delta wing mixer. Shazam Williams and Ming Chen studied the velocity and ammonia distribution in the straight pipe together with static mixer having two rows of tabs [23]. Azael and Ibarra investigated the interaction of fluid with a double vortex mixer to improve the performance of SCR. The evaporation effect and droplet crushing was significantly improved. The distribution of $\mathrm{NH}_{3}$ was also studied, revealing a smooth and uniform distribution using a double vortex mixer; however, the velocity uniformity distribution, reaction temperature, and droplet distribution time was not studied [24]. One of the disadvantages of the SCR system is that it occupies the additional space on vessels. Mostly, authors are working to simplify the SCR system according to the space requirements. One of the authors used an $18 \mathrm{~mm}$ distance between the two mixers without considering the impact of velocity on SCR system [18]. Park et al. reported that if the continuous uneven impact of velocity occurs, which causes excessive aerodynamic velocity and temperature, it will lead to the thermal fatigue failure, which reduces the service life [25]. The first mixer can create turbulence intensity and sudden impact on velocity, which directly affects the second mixer. By considering both of the references, it can be perceived that the optimum condition which can satisfy both of the conclusions from different studies can lie within limits. It therefore looked suitable to trial for $0.2 \mathrm{~m}$ distance. One of the study used series of only swirl mixer (SM) near the injection point and in line [18]. However, use of a line mixer (LM) can result in increasing the mixing flow (exhaust gas plus urea droplets) in the blind corner near the pipe wall, while SM results in increasing the mixing flow in the center [25]. Some studies investigated LM with different blade angles [25,26], 
and others used SM with different blade angles $[18,27]$. In this study LM was used in front of SM. Initially, LM and SM were used separately and then analyzed for the combined effect of both (LSM). In this work, the blade angle was $45^{\circ}$ for both mixers because it has been proven that static mixers consisting of bitched blades with an angle of inclination angle of $45^{\circ}$ can generate higher turbulence intensity and a swirling flow in the pipe [28]. Furthermore, many authors have used a greater number of blades than this study. One author used 36 blades in only LM [25]. In this study, 18 (LM:12, SM:6) blades were used and distributed in two difference places in the pipe. In addition, if a single mixer has many blades at a certain location, it tends to decrease the wall temperature, which ultimately results in deposit formation [29]. Hence it is necessary to distribute number of blades in two mixers with different locations to increase the mixing performance and prevents deposit formation. Generally, SCR performance depends upon the velocity uniformity and ammonia uniformity near the inlet of the SCR catalyst. Therefore, a suitable design of mixers for increasing the efficiency of SCR is needed. Furthermore, a numerical model has been developed, which describes the impact of mixer on the ammonia and velocity uniformity, droplet residence time, and temperature distribution in the pipe. In addition, it is also necessary to consider reaction temperature and wall temperature, as it affects the catalyst performance and deposit formation [1]. In this paper, two different types of mixers-line (LM) and swirl (SM) type mixers alone and in combination (LSM)-were used to indicate the effects on the performance of SCR. The main objective of this investigation is to create the optimum SCR design, to achieve higher uniformity index for velocity and ammonia distribution, better evaporation rate, and droplet distribution by consideration of the reaction temperature and wall temperature distribution based on CFD. Furthermore, for the verification of the simulated results of ISO 8178 a standard marine Diesel engine test cycle E3 was used [30].

\section{Computational Model Formulation}

\subsection{Geometric Model}

The complications in the design and arrangements of SCR system leads to difficulties in the uniformity of flow field and ammonia in the exhaust flow by using only urea water solution (UWS) and species diffusion. It is therefore necessary to use static mixer to optimize the mixing of exhaust gas flow with UWS. It has been proved by previous studies that uniformity of flow velocity and ammonia distribution can be increased with a suitable mixer, which directly enhances the performance of SCR catalyst. The optimized mixers have ability of complete rapid mixing of UWS droplet with exhaust gas which accelerates the pyrolysis reaction. Therefore, the catalyst conversion efficiency was improved [31].

In this study, two different types of mixers are used-line type mixer (LM) and swirl type (SM). In the first part of study, the SCR performance was analyzed by LM and SM separately. The second part of study focused on the combined effects of LM and SM. The distance between two mixers was kept $0.2 \mathrm{~m}$. The pipe diameter was $100 \mathrm{~mm}$. Injection point was located $0.1 \mathrm{~m}$ away from the $\mathrm{LM}$ and $0.3 \mathrm{~m}$ away from the SM, when both mixers were used together. For the single mixer, the position was taken as $0.1 \mathrm{~m}$ away from the injection point. The complete systematic design of SCR system is represented in Figure 1.

The design of LM includes $4 \times 4$ rows of blades and the angle of blades with horizontal plane was $45^{\circ}$. This design represents the improved heat transfer efficiency and abolishes the blind corners. Four blades were used at the center rows while two at the corners. One column of blades shows a downward direction and the other shows an upward direction. The design construction of SM was adopted in order to enhance the breakup effect of droplets and increase the turbulence intensity which ultimately results rapid mixing and pyrolysis of urea. The SM mixer possess six number of blades tilted at an angle of $45^{\circ}$ with the horizontal. By analyzing the result of individual mixers on SCR performance, a system was designed using both LM and SM in combination to achieve an improvement in performance. Considering the complexity of SCR system, the mesh grid is generated by tetrahedral method for 
adequate adaptation as shown in Figure 2. Away from the solid wall boundary, the grid was stretched which was the good comprise between the mesh points and computational costs. Furthermore, mesh independence test has been performed to calculate the ammonia uniformity without using any mixer, as shown in Figure 3. After mesh independence analysis, the total number of cells in the mesh system was 1.8 million; because a further increased in mesh cells has no significant effect on the uniformity index.

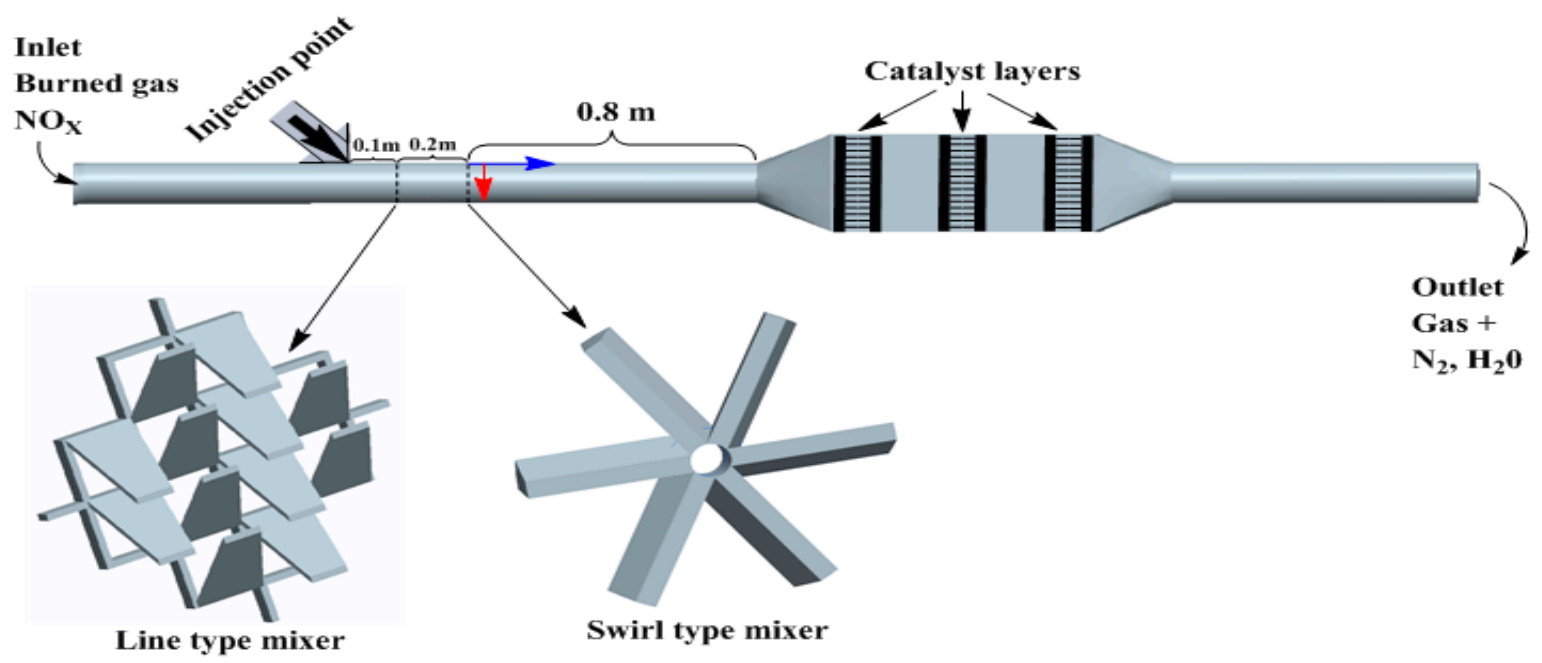

Figure 1. Systematic structure of the selective catalyst reduction (SCR) system.

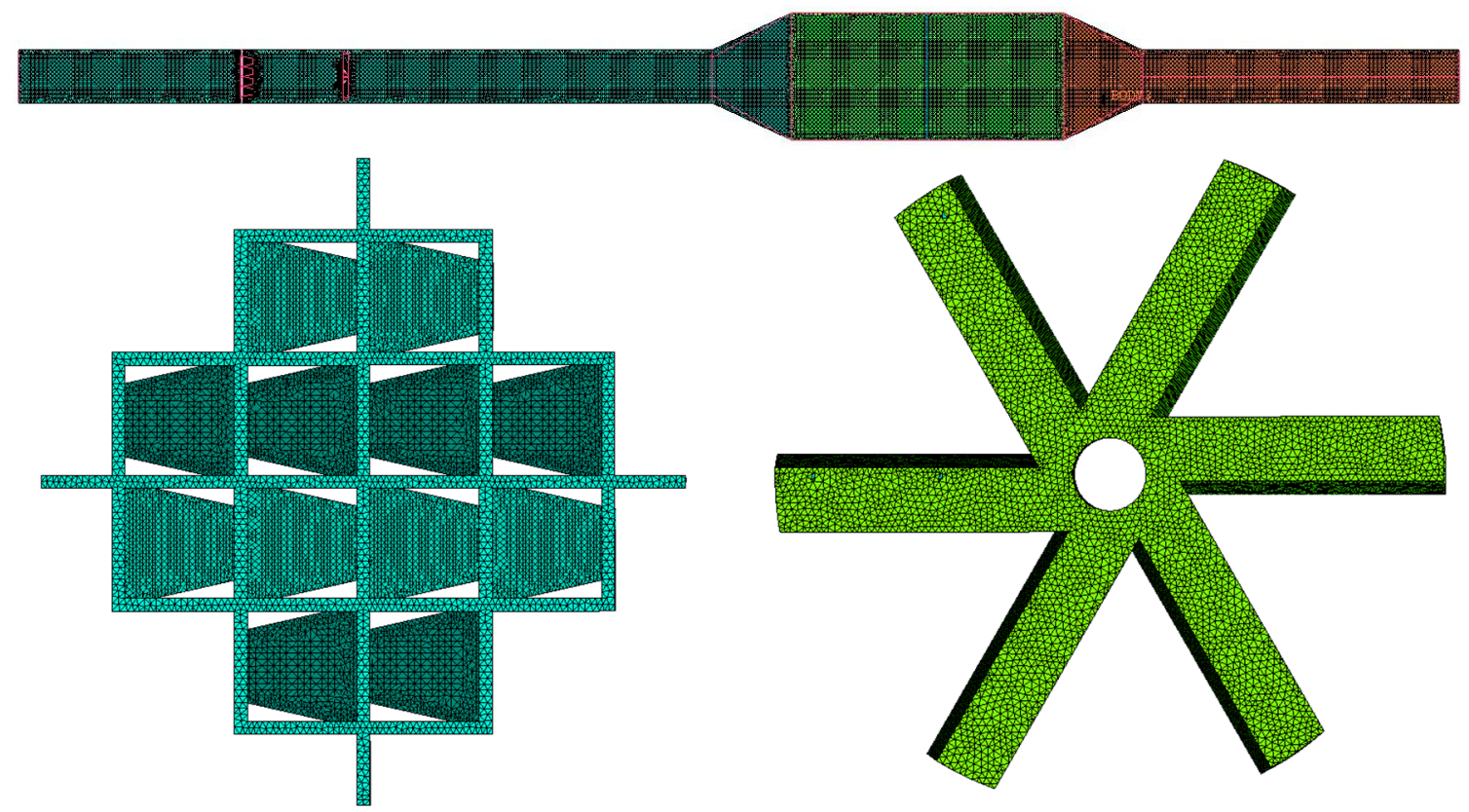

Figure 2. Mesh grids of computational domain. 


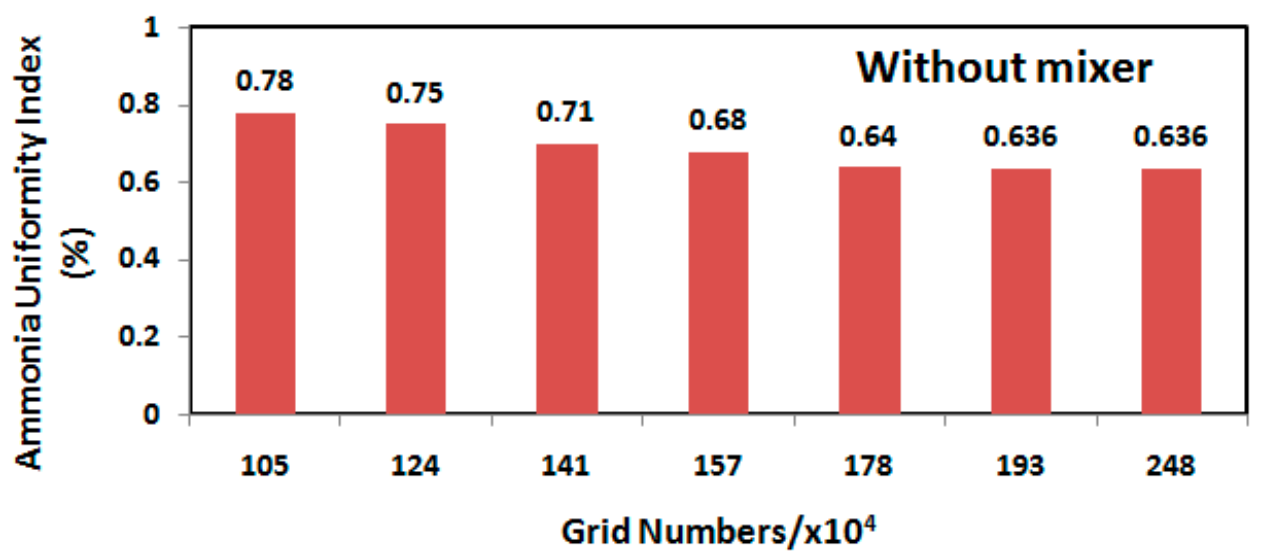

Figure 3. Mesh grid independence analysis.

\subsection{Numerical Procedure}

Numerical studies have been done for the optimum design of SCR system in the form of flow uniformity and the reduction of $\mathrm{NO}_{\mathrm{X}}$ emissions [22,32]. In this study, the flow field distribution of velocity was taken uniform and thermal expansion in the catalyst was negligible. Exhaust gases from the engine were adopted as the ideal gas mixture in the CFD. Incompressible steady flow was used. The flow was simulated by using the standard $K$-epsilon model $(K-\varepsilon)$ in combination with wall treatment function to evaluate the turbulent flow velocity in the exhaust system because the Reynolds number is usually very high in an exhaust pipe. It is a two equation model that gives a general description of turbulence by means of two transport partial differential equations. The first transported variable is the turbulence kinetic energy $(K)$ and the second transported variable is the rate of dissipation of turbulence energy $(\varepsilon)[25,33]$. The injection and decomposition process of UWS were simulated by transport model. Evaporation and decomposition performances were described by using a mixture model of multicomponents. The concentration of $32.5 \mathrm{wt} \%$ UWS was injected at the temperature window of $313 \mathrm{~K}$. Pressure swirl atomizer was used for injection of UWS. KH-RT model was used for breakup of droplet. Firstly, water was evaporated from urea droplets during decomposition. The rate of water evaporation was predicted by Raouli's law of multi component mixture. Raoult's law is based on the assumptions that the vapor phase behaves as an ideal gas and the liquid phase is an ideal solution in mixing of the flow. The rate of water evaporation can be obtained by Equation (1).

$$
\frac{d m}{d t}=M W_{\text {water }} k_{c}\left(\frac{x_{\text {water }} P_{\text {sat }, \text { water }}}{R T_{P}}-C_{\text {water }}\right)
$$

If the fraction of water in UWS is going beyond the threshold value (0.01), then the UWS droplets are considered as the particles of urea and it can be easily calculated by the decomposition reactions of urea particles. As the urea particles react with exhaust gas species, it results in $\mathrm{NH}_{3}$ and $\mathrm{HNCO}$. The mass change rate can be obtained by Equation (2).

$$
\frac{d m_{P}}{d t}=M W_{i} \sum_{r=1}^{N_{R}} R_{i, r}
$$

The species transport and continuity equation are used to define the variation of gases produced from decomposition reactions such as $\mathrm{NH}_{3}, \mathrm{CO}_{2}$, and $\mathrm{HNCO}$ (Equations (3) and (4)).

$$
\begin{gathered}
\frac{\partial\left(\rho Y_{i}\right)}{\partial t}+\nabla \cdot\left(\rho \vec{V} Y_{i}\right)=-\nabla \cdot \overrightarrow{J_{i}}+R_{i}+S_{i} \\
\frac{\partial \rho}{\partial t}+\nabla \cdot(\rho \vec{V})=S_{m}
\end{gathered}
$$


By concentration gradients, the mass diffusion in laminar flows used and it was modeled by Fick's law, as shown in Equation (5).

$$
\vec{j}_{i}=-\rho D_{i, m} \nabla Y_{i}-D_{T, i} \nabla T / T
$$

The turbulence due to turbulent diffusion is directly responsible for the quick mixing and species transport in turbulent flows therefore the mass diffusion can be obtained by Equation (6).

$$
\vec{j}_{i}=-\left(\rho D_{i, m}+\mu / S c_{t}\right) \nabla Y_{i}-D_{T, i} \nabla T / T
$$

The diffusive process is modeled by using turbulent diffusivity $\left(D_{T}\right)$ in the $K$ - $\varepsilon$ model. The $D_{T}$ can be obtained from Equation (7) [34].

$$
D_{T}=v_{T} / S c_{t}
$$

Schmidt turbulence number $\left(S c_{t}\right)$ is usually taken as 0.7. In the turbulence model, the turbulent diffusivity $D_{T}$ directly depends upon the use of turbulent viscosity $V_{T}$. Turbulent viscosity is obtained from given formula in the $K-\varepsilon$ model Equation (8).

$$
v_{T}=C_{u} k^{2} / \varepsilon
$$

In the $K-\varepsilon$ model, closure coefficient $\left(C_{u}\right)$ is taken as 0.09 .

Energy dissipation rate and turbulent kinetic energy are obtained from a standard two-layer $K-\varepsilon$ turbulent model as showed in Equations (9) and (10), respectively.

$$
\begin{gathered}
\frac{\partial k}{\partial t}+\frac{\partial u_{i} k}{\partial x_{i}}=\frac{\partial}{\partial x_{i}}\left(\left(v+\frac{v_{t}}{\sigma_{k}}\right)+\frac{\partial k}{\partial x_{i}}\right)+G-\varepsilon \\
\frac{\partial \varepsilon}{\partial t}+\frac{\partial u_{i} \varepsilon}{\partial x_{i}}=\frac{\partial}{\partial x_{i}}\left(\left(v+\frac{v_{t}}{\sigma_{\varepsilon}}\right)+\frac{\partial \varepsilon}{\partial x_{i}}\right)+\frac{\varepsilon}{K}\left(C_{\varepsilon 1} G-C_{\varepsilon 2} \varepsilon\right)
\end{gathered}
$$

where,

$$
\begin{gathered}
G=-\overline{u_{i} u_{i}} \frac{\partial u_{i}}{\partial x_{i}}=v_{t}\left(\frac{\partial u_{i}}{\partial x_{i}}+\frac{\partial u_{i}}{\partial x_{i}}\right) \frac{\partial u_{i}}{\partial x_{i}}, \text { and } v_{t}=C_{\mu} \frac{K^{2}}{\varepsilon} \\
C_{\varepsilon 1}=1.44, C_{\varepsilon 2}=1.92, C_{\mu}=0.09, \sigma_{K}=1.0, \sigma_{\varepsilon}=1.3
\end{gathered}
$$

For describing the conservation equation of gas-liquid phase and spray phenomenon, the discrete phase model was used. By the discrete phase model under the Lagrangian coordinate system, it could be constructed a governing equation to analyze the motion law of droplet and motion of liquid droplet which can be given by Equation (11).

$$
\frac{d \vec{u}_{p}}{d t}=\frac{\vec{u}-\vec{u}_{p}}{\tau_{r}}+\vec{g} \frac{\left(\rho_{p}-\rho\right)}{\rho_{p}}+\vec{F}
$$

Gradient diffusion is responsible for the rate of vaporization at low vaporization rates [35]. Transportation of urea droplet vapor was made at the bulk of gas and droplet surface because of the concentration gradient. At high vaporization rates, the fluctuation of urea water droplets into exhaust gases is directly associated with the effects of evaporating species under convective flow [36]. UWS droplets include the mixtures of two parts; therefore, the evaporation of UWS is separated into two different periods. During the first stage of decomposition, contents of water evaporate quickly from UWS droplets. In the later stage, molten urea evaporates [37,38]. In this study, UWS droplets were taken as multicomponent, therefore the total vaporization rate of UWS is the sum of vaporization rates for all UWS components. The evaporation of urea solution is the heat and mass transfers between the urea droplet and exhaust gases. Diffusion is controlled by concentration gradients described by 
Fick's law which was used as diffusion also occurs in multispecies systems that are experiencing the Stefan flow also and the model included the internal recirculation and Stefan flow effects [39].Thus the evaporation rate can be described by Equation (12).

$$
m_{p} c_{p} \frac{d T_{P}}{d t}=h A_{P}\left(T_{\infty}-T_{P}\right)-\frac{d m_{p}}{d t} h_{f g}+\varepsilon_{p}+A_{p} \sigma\left(\theta_{R}^{4}-T_{p}^{4}\right)
$$

Radiation properties are very complex to be described by the flow and have less importance. It was therefore neglected in our study. Moreover, some studies also have neglected this effect due to the complexity of system $[25,26]$.

A honeycomb-type catalyst is often used in the SCR system, and its single channel is very small to the outline size of the catalyst [32]. In this study, the catalytic reaction section was taken as a multiple holes section, and the porous medium model was adopted for evaluation. In the porous medium model, the momentum source term was included to the momentum equation and showed in Equation (13).

$$
S_{i}=-\left(\sum_{j=1}^{3} D_{i j} \mu v_{j}+\sum_{j=1}^{3} C_{i j} \frac{1}{2} \rho\left|v_{j}\right| v_{j}\right)
$$

If each position of catalyst has the same nature in gas convection and diffusion in the channel are ignored, the above equation can be simplified as Equation (14).

$$
\nabla p=-\frac{\mu}{\alpha} v
$$

\subsection{Boundary Conditions}

CFD boundary conditions were selected according to the ISO standard 8178 marine Diesel engine. The initial temperature and exhaust flow rate before the catalyst reactor weretaken as $327^{\circ} \mathrm{C}$ and $1.6 \mathrm{~kg} / \mathrm{s}$, respectively. The quantity of $\mathrm{NO}_{\mathrm{x}}$ emission was $256 \mathrm{ppm}$. The inlet and outlet diameter of catalyst reactor were $100 \mathrm{~mm}$. The boundary conditions at the inlet of catalytic reactor was set to the mass flow rate, turbulent kinetic energy was set as $6 \%$ of the average velocity, and the characteristic length was $10 \%$ of the inlet diameter. The boundary condition at the outlet of catalytic reactor was defined as outlet pressure and the outlet pressure was same as atmospheric pressure. The boundary conditions at the wall of catalytic reactor were set as nonslip velocity and frictionless. The material is defined as iron.

The working parameters of the SCR system are shown in Tables 1 and 2. The working process of the SCR system was studied and simulated in this paper. Flow rate, temperature at the diesel exhaust, exhaust pressure, and urea injection rate increased with respect to engine load. Furthermore, urea water solution was injected by using air assisted injector at the upstream of mixer with the ten numbers of streams. Pressure atomizer injector was used with the injection hole diameter of $0.0007 \mathrm{~m}$. The spray angle was kept $60^{\circ}$ with spray pressure of 6 bar. The rate of multitude hole was 0.89 in the porous medium model. The thermal conductivity of solid phase coefficient was taken as $1.7 \mathrm{~W} /(\mathrm{m} \cdot \mathrm{k})$ and the specific heat capacity was $1016 \mathrm{~J} /(\mathrm{kg} \cdot \mathrm{k})$.

Table 1. Exhaust conditions of marine Diesel engine.

\begin{tabular}{ccccc}
\hline Parameters & $\mathbf{2 5 \%}$ & $\mathbf{5 0 \%}$ & $\mathbf{7 5 \%}$ & $\mathbf{1 0 0 \%}$ \\
\hline Flow $(\mathrm{kg} / \mathrm{s})$ & 0.516 & 1.2 & 1.63 & 1.94 \\
Pressure $(\mathrm{bar})$ & 1.4 & 2.17 & 3.1 & 3.8 \\
Temperature $\left({ }^{\circ} \mathrm{C}\right)$ & 254 & 290 & 327 & 395 \\
Urea Injection $(\mathrm{kg} / \mathrm{s})$ & 0.0091 & 0.013 & 0.0161 & 0.0192 \\
\hline
\end{tabular}


Table 2. Injection system and catalyst conditions.

\begin{tabular}{lcc}
\hline & Parameters & Value \\
\hline \multirow{3}{*}{ Injection Conditions } & Injection type model & Pressure swirl atomizer \\
& Injection inner hole diameter & $0.0007 \mathrm{~m}$ \\
& Urea temperature & $313 \mathrm{k}$ \\
& Number of streams & 10 \\
\hline \multirow{3}{*}{ Catalyst Conditions } & Inverse absolute Permeability $\left(\mathrm{m}^{-2}\right)$ & 1.85 \\
& Inertia resistance $\left(\mathrm{m}^{-1}\right)$ & 85 \\
& Porosity & 0.89 \\
& Surface to volume ratio $(1 / \mathrm{m})$ & 1275 \\
\hline
\end{tabular}

\section{Results and Discussion}

\subsection{Uniformity}

Catalyst efficiency depends upon the two important parameters: flow velocity uniformity and uniform distribution of ammonia. Long-time irregular scattering and non uniformity of flow velocity will cause the excessive aerodynamic velocity and temperature, which directly impacts the structure and performance of catalyst. As the result, thermal stress can be developed, which leads to the fatigue failure and effects the service life of catalyst [25]. It is therefore recommended that the velocity of UWS must be well distributed as much as possible, at the front of the SCR catalyst reactor inlet. Equation (15) can be used to calculate the uniformity index of flow velocity and ammonia distribution.

$$
U I_{\text {flow }}=1-\frac{1}{2} \sum_{i=1}^{n} \frac{\left|V_{i}-V_{\text {mean }}\right| A_{i}}{A V_{\text {mean }}}
$$

\subsubsection{Velocity Uniformity}

The distribution of velocity field of LM, SM and the combination of both (LSM) is represented in Figure 4 . The exhaust gases flow with LM was initially very uneven; downstream of mixer at the center of pipe. Furthermore, a baffle gap was also generated at the downstream but the velocity distribution inside the baffle seems smooth. As the distance was increased to the reactor inlet, uniformity was also increased, as shown in Figure 4a. SM effectively created the rotational air flow generating swirling mixing flow at the pipe wall. Swirl flow shows well mixing of exhaust gases and urea solution. Moreover, a high baffle gap was produced at the downstream of mixer, but the velocity distribution inside the baffle was highly uneven. However, flow velocity of mixture at the middle seems comparatively low as in Figure $4 \mathrm{~b}$.

Figure 4c showed the combined effects of LM and SM. In comparison with pure rotating blade and line type blade structures of SM and LM, respectively, the velocity uniformity was enhanced when LSM was employed. The arrangement of LSM not only generated a strong swirl flow beside the mixer wall, but also increased the velocity near the wall of pipe.

Catalyst effectiveness and utilization rate directly depends on the velocity uniformity index of UWS and exhaust gas mixture along the axial direction at the catalyst reactor inlet. The relation of the velocity uniformity index from the mixer downstream to catalyst reactor inlet is shown in Figure 5. Uniformity index of flow velocity of LM, SM, and LSM mixers were calculated as $0.93,0.86$, and 0.95 at the upstream of reactor inlet $(0.8 \mathrm{~m})$, respectively. Uniformity index of LSM at the downstream of mixers $(0.1 \mathrm{~m})$ is relatively low because of continuous and sudden impacts of two mixers on the flow velocity. However, with the increase of distance the uniformity of velocity for LSM was greatly improved due to the turbulence outcome produced from the sudden impact effect of two mixers. Therefore, the overall uniformity index of flow velocity of LSM before the reactor inlet was relatively high as compared to LM and SM. 


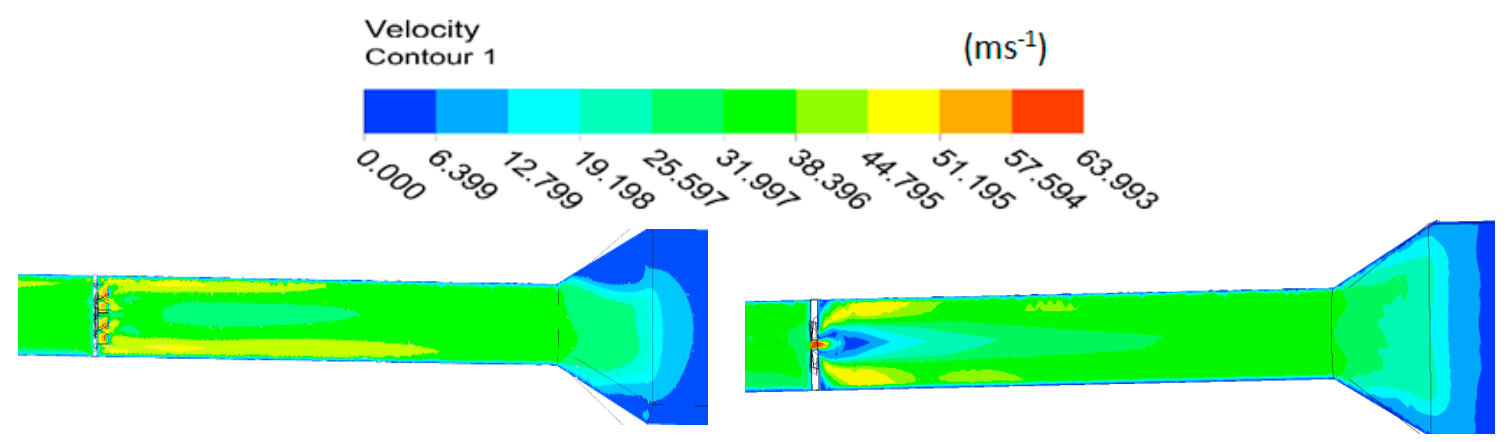

(a)

(b)

(c)

Figure 4. Velocity contour maps. (a) Line (LM) type mixer, (b) swirl (SM) type mixer, and (c) two mixers (LSM).

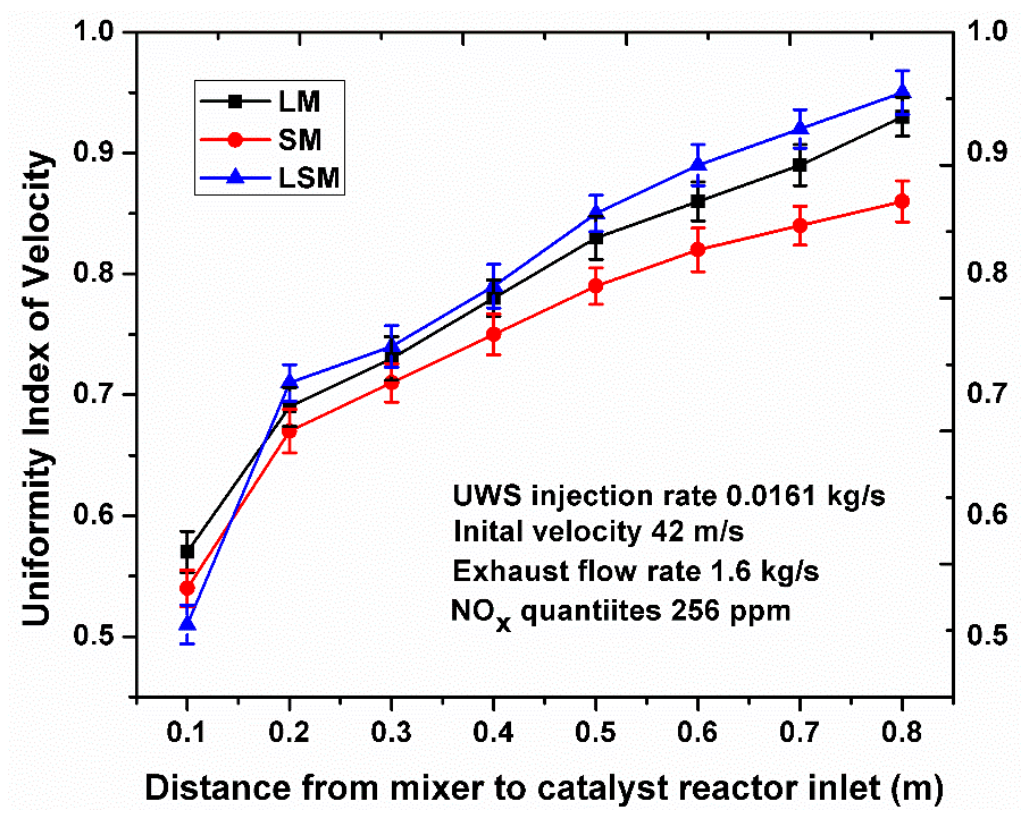

Figure 5. Distribution of velocity uniformity.

To illuminate the SCR reactor internal stability and uniformity index of flow velocity, the distribution at the reactor entrance was extracted and is shown in Figure 6. The main objective of displaying the velocity uniformity at the reactor inlet was to remove the turbulence effect produced by mixers and to show actual velocity distribution more clearly. Figure $6 a, c$ shows that the exhaust gases gained high turbulent kinetic energy, resulting in the better velocity uniformity. However, SM (Figure 6b) shows that the radial velocity gradient was high and resulted in poor uniformity, but the velocity flow was slightly decreased with the increase of distance. 


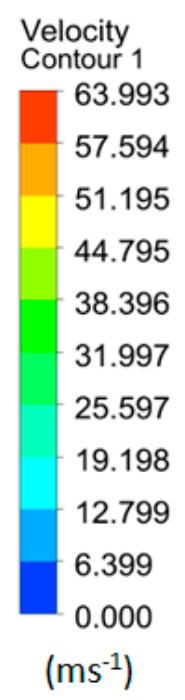

$\left(\mathrm{ms}^{-1}\right)$

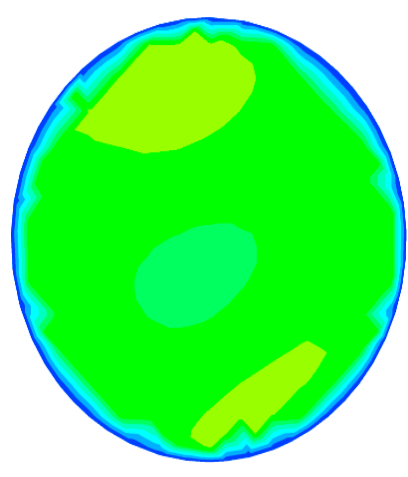

(a)

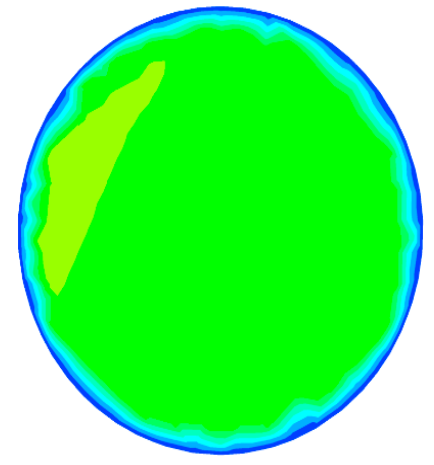

(b)

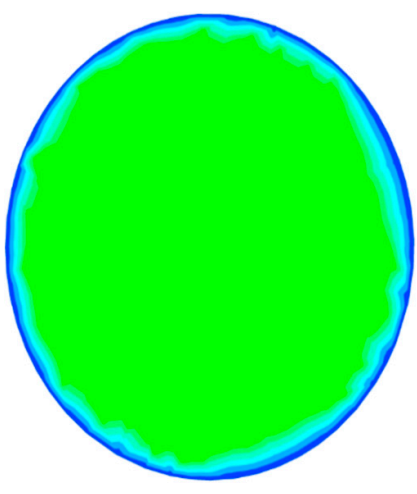

(c)

Figure 6. Velocity contour maps at the inlet of catalyst inlet. (a) Line (LM) mixer, (b) swirl (SM) mixer, (c) and two mixers (LSM).

\subsubsection{Ammonia Uniformity}

The irregular and insufficient ammonia distribution will result in $\mathrm{NO}_{\mathrm{X}}$ escape [40,41]. The $\mathrm{NH}_{3}$ uniformity distribution is an important index of the SCR system for estimating performance [42-44]. The water from the urea droplets evaporates entirely and converts urea in $\mathrm{NH}_{3}$ gas when it reaches to reactor inlet. Reductant uniformity index is the most significant factor used to evaluate, whether the catalyst will achieve the highest denitrification rate and lowest ammonia leakage. The plane was created in CFD at a certain distance/area and then divided the plane into the number of points and finds the mass fraction of ammonia on each single point. After that, the standard deviation and average value of all the points were calculated. Finally, the formula for the uniformity index was used to find ammonia uniformity at certain distances. The ammonia uniformity index from the mixer downstream to catalyst reactor inlet in the axial direction was calculated and is shown in Figure 7. The $\mathrm{NH}_{3}$ uniformity distribution of LM, SM, and LSM were calculated as $0.87,0.94$, and 0.96 at the upstream of reactor inlet, respectively.

Ammonia uniformity index of LSM at the downstream of mixers is relatively low due to uninterruptedly and sudden impacts of two mixers continuously. However, the uniformity index of ammonia of two mixers was greatly enhanced with the increase of distance due to high turbulence outcome produced from the impact effect of two mixers. Hence, generally, the ammonia uniformity index is the combination of two (line and swirl type) mixers before the catalyst reactor inlet is relatively high, as compared with the separately use of line and swirl type mixers.

Uniformity index of ammonia distribution at the outlet of reactor inlet was extracted to clarify the result as much as possible and showed in Figure 8. At first, the plane was created in CFD at the catalyst inlet, plane was divided into number of cells and value of molar concentration of ammonia at each single point was calculated. Next, the standard deviation and average value of ammonia concentration at the catalyst inlet were calculated. Finally, the uniformity index was used to calculate the ammonia uniformity at catalyst inlet. In LM, a high concentration of ammonia distribution is located at the upper side of the pipe wall, and some places at the mid of pipe also show that ammonia distribution was not smooth (Figure 8a), resulting in poor catalyst performance. In SM, ammonia seems well distributed as a whole but the small area at the upper side of pipe shows the high concentration (Figure $8 b$ ). Distribution of ammonia was greatly improved when using LSM and much less ammonia was deposited at sides and center (Figure 8c). 


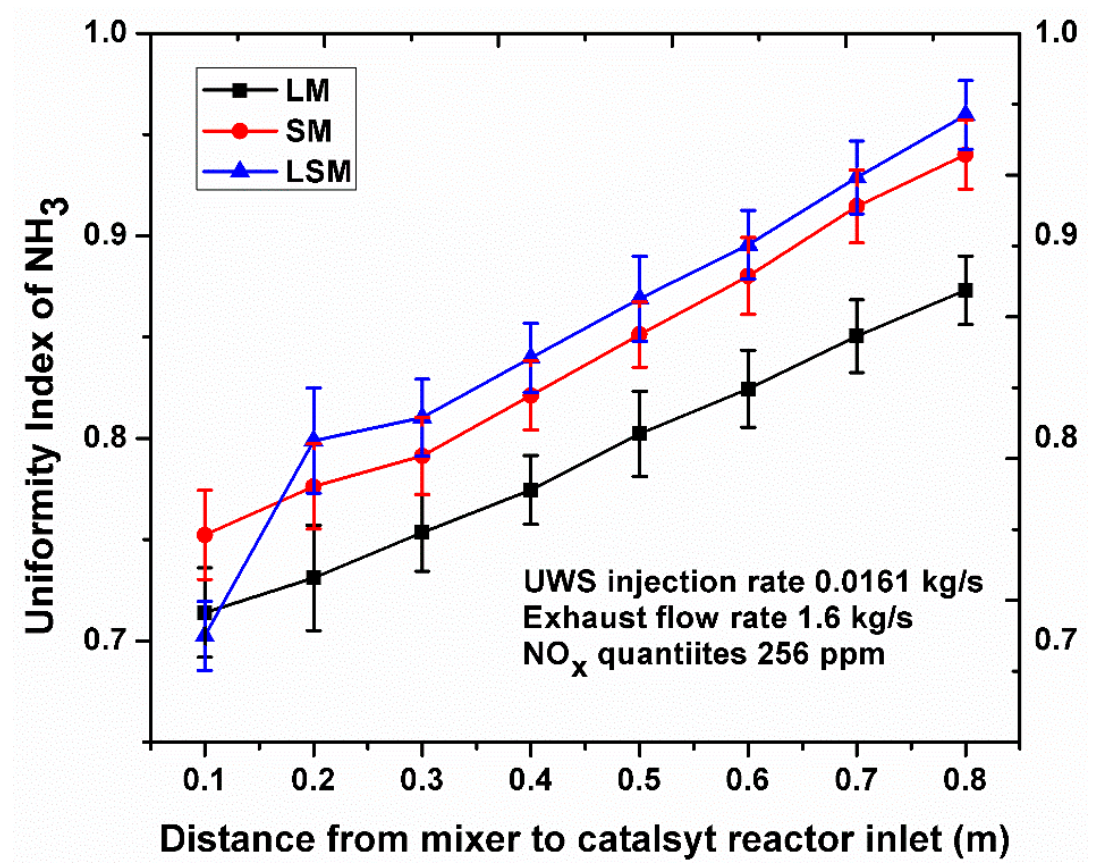

Figure 7. Distribution of ammonia uniformity.

Nh3.Molar Concentration Contour 1

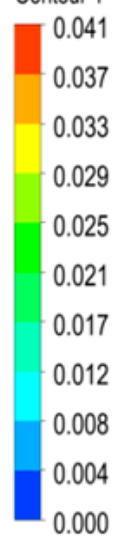

$\left(\mathrm{mol} \mathrm{m}^{-3}\right)$

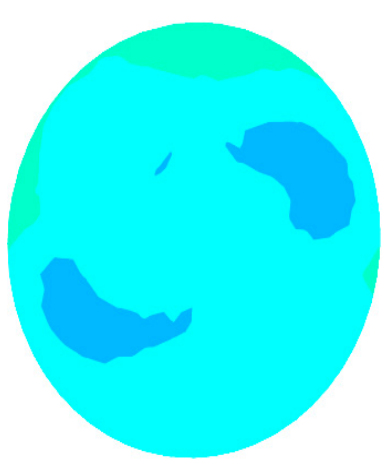

(a)

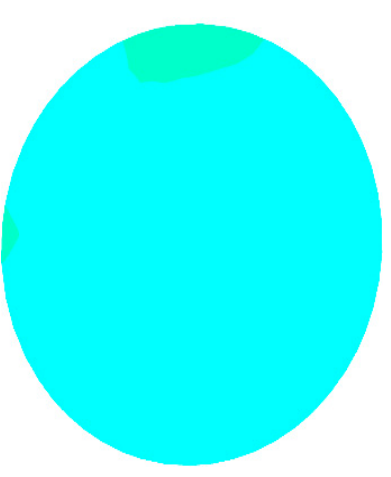

(b)

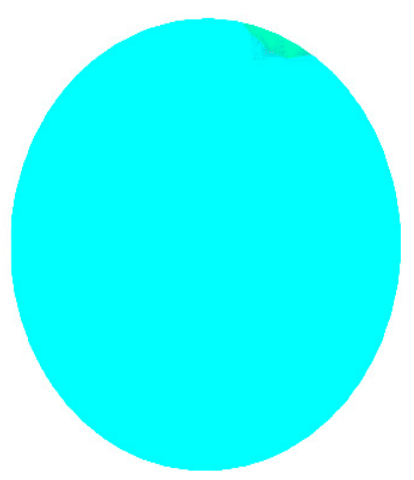

(c)

Figure 8. Velocity contour maps at the inlet of catalyst inlet. (a) Line (LM) mixer, (b) swirl (SM) mixer, and (c) two mixers (LSM).

The values of indexes of the velocity and ammonia uniformity of LM, SM, and LSM from the location of mixer downstream to catalyst reactor inlet are tabulated in Table 3. It is very clear that LM reveals a good uniformity index for velocity but, on the contrary, it exhibits a poor uniformity index for ammonia. SM behaves opposite to the LM: it possesses good ammonia uniformity but shows poor velocity distribution.

Table 3. Uniformity index at the inlet of the catalyst reactor.

\begin{tabular}{cccc}
\hline Uniformity Index & LM & SM & LSM \\
\hline Velocity Uniformity & 0.93 & 0.86 & 0.95 \\
Ammonia Uniformity & 0.87 & 0.94 & 0.96 \\
\hline
\end{tabular}


It is difficult to obtain the good uniformity of the both important indicators at the same time while using only single mixer. In comparison, LSM can be categorized with the good uniformity for both, the velocity and ammonia distribution due to high turbulent intensity. The values calculated for uniformity were 0.95 and 0.96 for the velocity and ammonia, respectively. For the purpose of mass transfer and homogenization, when the mixture species passes through the second mixer of LSM, it creates swirl and endorse the mass transfer effect near the pipe wall. The shear and swirl flows with the pipe wall produce molecular diffusion and eddy diffusion under forced convection. Hence, the mixing of ammonia with exhaust gases is comparatively sufficient which results the effective improvement in the uniformity of velocity and ammonia, simultaneously.

\subsection{Droplet Residence Time}

UWS injection in the exhaust gases lowers the temperature of the gas phase due to heat transfer phenomena. Figure 9 represents the UWS droplets residence time for diameter ranges from $0.007 \mathrm{~mm}$ to $0.07 \mathrm{~mm}$. The plane was located at the downstream of injector. By counting the frequency of droplets with different diameters to pass through the plane for calculation purpose, the plane was divided into number of sections with each section having a fixed width. Each section was analyzed for the droplet, which was assumed to be spherical. After that, each droplet diameter was calculated from droplet volume obtained by taking into account the volume fraction occupying the computational meshes. Also, the cumulative probability distribution function was used to describe the probability of finding the diameter of the secondary droplets in a sample of splashing drops. The mass of splashing droplets from the wall depends upon the splashing energy of the droplets [45]. In the system of LM, SM, and LSM, while the UWS droplets were injected into the gas phase, the UWS droplets residence time ranged from $0.004 \mathrm{~s}$ to $0.121 \mathrm{~s}, 0.004 \mathrm{~s}$ to $0.091 \mathrm{~s}$, and $0.004 \mathrm{~s}$ to $0.064 \mathrm{~s}$, respectively. From this analysis, the LSM-installed system showed obvious differences of $47 \%$ and $29 \%$ decreases of residence time compared to LM and SM, respectively.

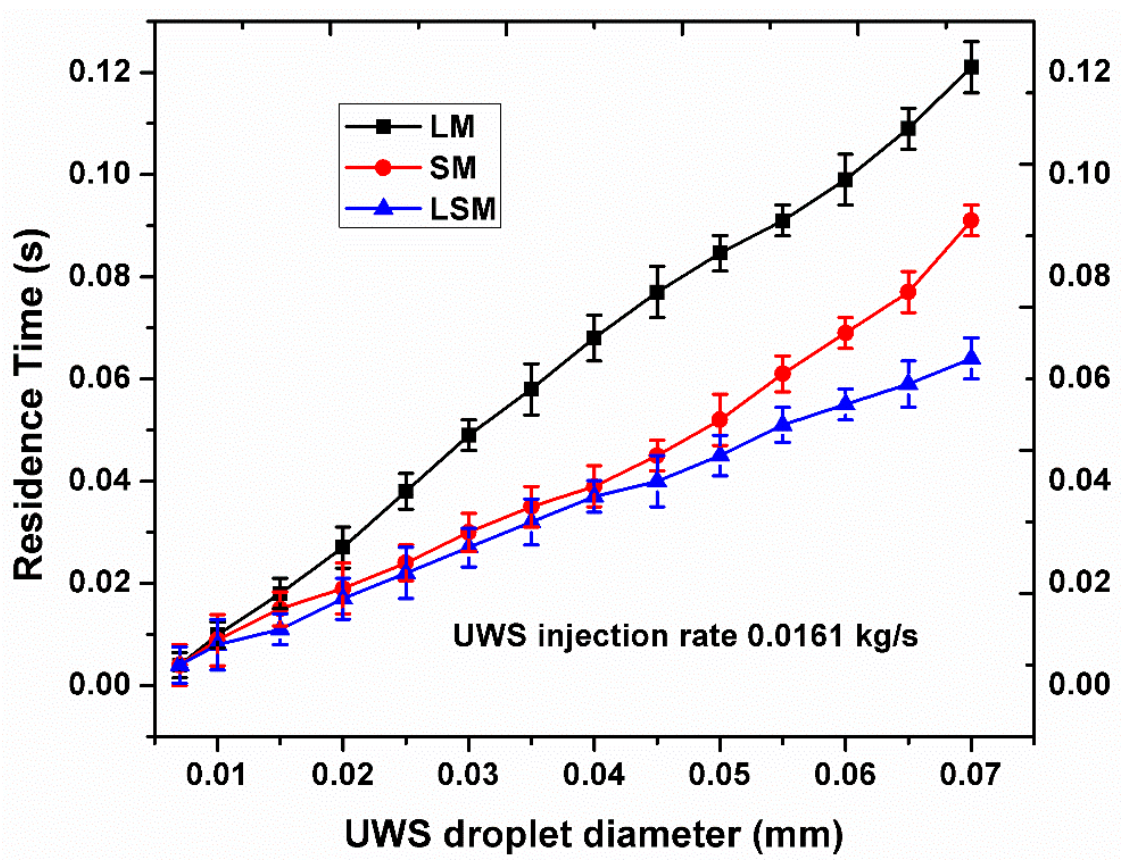

Figure 9. Residence time of urea droplets with the use of different mixers.

The angle of injection of UWS was 30, and the injection was done at the center of pipe; therefore, it is difficult for droplets to move far in radial directions but as an alternative of it, droplets will try to moves toward center. The droplets with bigger diameter will not follow the flow but start to move in radial directions. Small droplets evaporate faster than the bigger diameter and can easily be blown to 
the center of pipe. However, with the use of LSM, the mixing ability of UWS droplets and exhaust gas enhance sufficiently, which resist the gathering of larger UWS droplets and avert the temperature drop at the center of pipe. Moreover, the combination of two mixers results to increase the turbulence intensity which produces high evaporation rate. Overall, in the system of LSM, the residence time of UWS droplets decreases not only due to the improvement in the distribution of droplets and but also due of high turbulence impact of two mixers.

\subsection{Urea Conversion}

Better conversion or evaporation of UWS results the enough production of ammonia for SCR reaction. With the use of mixers, primary UWS droplets can be distributed and broken up into secondary droplets resulting in quick evaporation of UWS. Conversion of urea from the mixer downstream to the catalyst inlet (Figure 1 blue arrow) for LM, SM, and LSM are shown in Figure 10. It has been observed that there is deficient conversion of urea with the use of single mixer. As the decomposition distance increases, the conversion of urea also increases gradually. For the system of LM and SM, the conversion of urea is $76.1 \%$ and $83.2 \%$, respectively. However, for the LSM system, the conversion increases up to $95.4 \%$. Urea conversion is directly related with the mixing of flow distribution and droplet residence time in the SCR system.

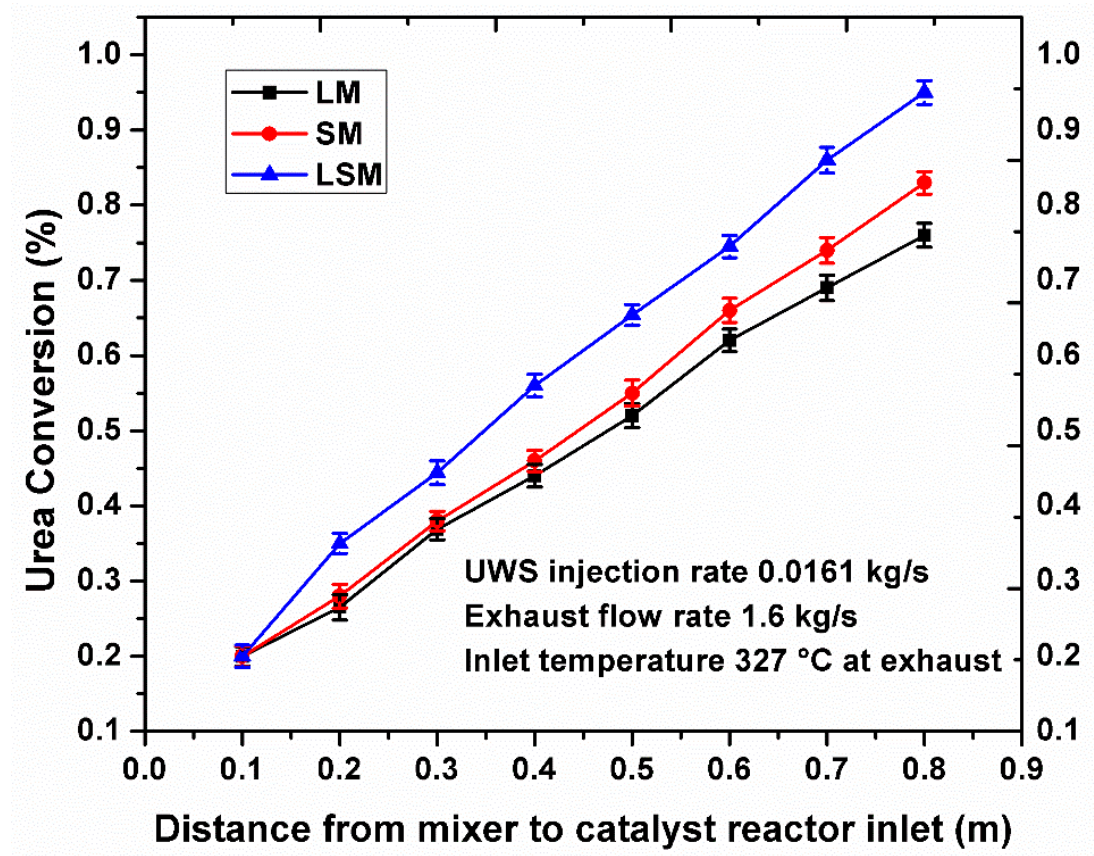

Figure 10. Urea conversion from mixer downstream to catalyst inlet.

Conversion of urea takes place in two stages, one is water vaporization stage, while the other urea vaporization stage as shown in Figure 11. Initially, the evaporation of pure water occurs from UWS droplets; therefore it becomes unstable in the exhaust gas in the later stage. As a result, the decomposition of urea produces $\mathrm{NH}_{3}$ and $\mathrm{HCNO}$. The droplets with bigger diameter can only undergo water vaporization stage and hence does not produces sufficient ammonia in long distances. With the use of LSM, bigger droplets are break up into small droplets and need short time to evaporate which ultimately results in increased evaporation rate. 


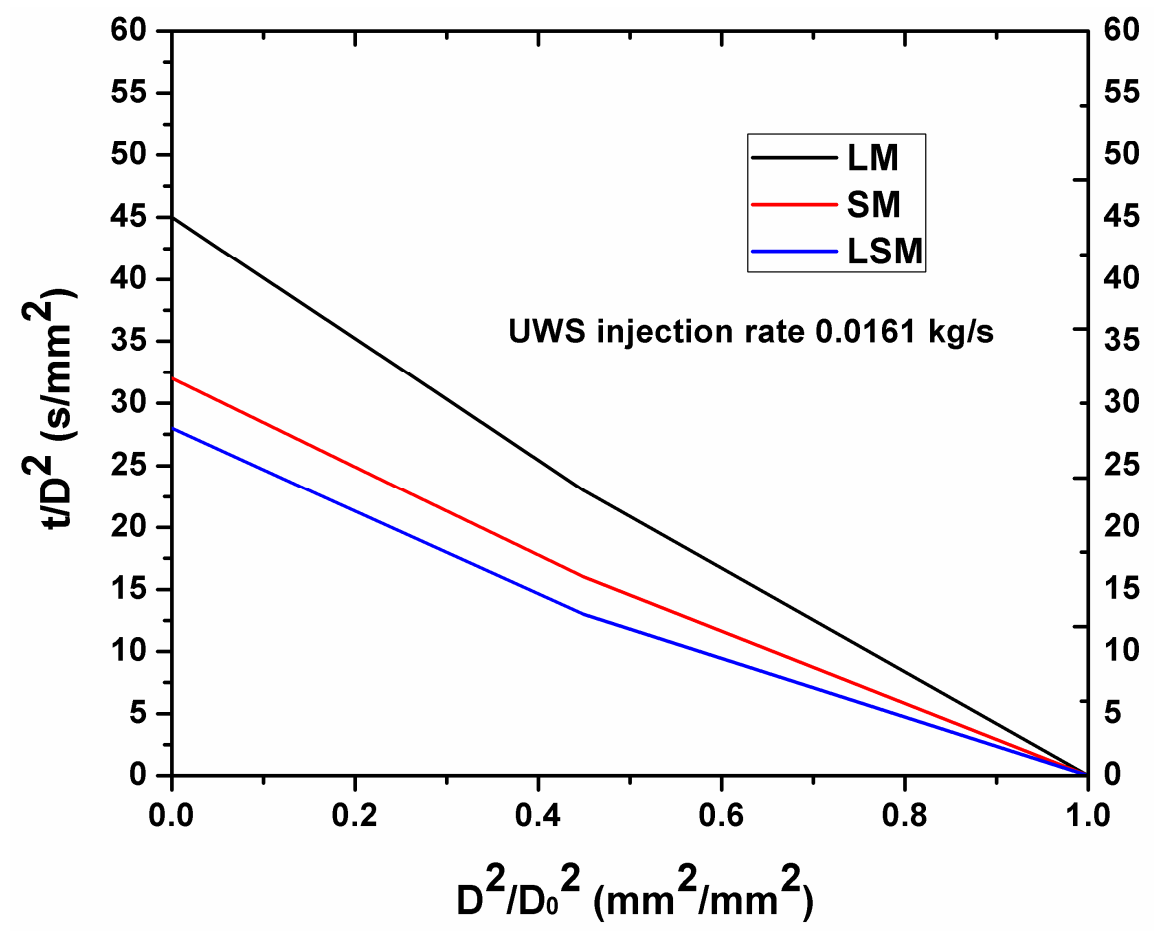

Figure 11. Urea water solution (UWS) droplet at two vaporization stages.

\subsection{Relation of Temperature with SCR Performance}

Two important factors relating to the SCR system temperature include deposit formation and catalyst reaction efficiency. SCR is a means of converting $\mathrm{NO}_{x}$ emissions into $\mathrm{N}_{2}$ and $\mathrm{H}_{2} \mathrm{O}$ by using the catalyst and $\mathrm{O}_{2}$ in the temperature window of 280 to $420{ }^{\circ} \mathrm{C}$ [11]. The rate of reaction will be slow and unwanted reactions will occur, if the temperature goes below $280^{\circ} \mathrm{C}$, resulting in poor SCR catalyst performance. Ammonia will start to burn without reacting with the $\mathrm{NO}_{\mathrm{x}}$ emissions if the temperature goes above $420^{\circ} \mathrm{C}$. It is therefore recommended to control the reaction temperature of SCR system [46].

The wall temperature is the prominent source for finding the deposit formation. Urea starts to decompose rapidly, associated with the secondary reactions, if the temperature is more than $163^{\circ} \mathrm{C}$. If the temperature is in between the range of 133 to $163{ }^{\circ} \mathrm{C}$, pyrolysis of urea occurs slowly. Urea crystals are formed certainly as temperature is reduced below $133^{\circ} \mathrm{C}$. Once the temperature goes down, urea crystals are produced and the exhaust pipe will be blocked, which is responsible for decreasing the mixing performance and increasing the back pressure [18]. Concurrently, the overall catalytic reactor efficiency is decreased considerably. Once the urea injected into the system, a number of small droplets produce collisions with the pipe wall and mixer. The increase in collision strength of droplets with pipe wall decreased the temperature. Under the Leidensforst temperature, droplets of urea are separated into four boiling phenomenon as maintained by three values of temperature: 140, 190, and $300{ }^{\circ} \mathrm{C}$. Heat transfer to the liquid film from pipe wall increased at $\sim 180^{\circ} \mathrm{C}$ [9]. If the wall temperature is lower than the boiling point temperature $\left(\mathrm{T}_{\mathrm{b}}\right)$ of the UWS droplet, the droplets will stick on the wall and, if the temperature is higher than $\mathrm{T}_{\mathrm{b}}$, the droplets will rebound after striking with the wall [45]. Therefore, it is important to obtain maximum liquid film temperature for improved performance of urea decomposition and decrease the deposit formation.

Temperature Distribution along the Mixer Downstream

The temperature distribution along the radial direction at the mixer downstream (Figure 1 red arrow) as represented in Figure 12. The pipe diameter is $10 \mathrm{~cm}$; therefore, the initial position $(0 \mathrm{~cm})$ stands for the upper edge of the pipe and $10 \mathrm{~cm}$ shows the position of lower edge. A plane was created in CFD at a certain distance and then divided into number of points. The value of temperature 
on each single point was found. Next, the standard deviation and average value of all the points were calculated. The minimum temperature of LM at the top edge is $274{ }^{\circ} \mathrm{C}$, which is $32{ }^{\circ} \mathrm{C}$ less than SM and LSM.As it has been proved that after the urea injection process a large number of droplets collide with the mixer and the pipe wall: the wall temperature decreases with the increase in collision intensity [29]. In all types of mixers arrangement, the temperature difference at the center of the pipe is not obvious. However, the temperatures of LM and SM at the bottom edge of pipe were $276{ }^{\circ} \mathrm{C}$ and $281{ }^{\circ} \mathrm{C}$, respectively. The temperatures at top edge and bottom edge of pipe are $304^{\circ} \mathrm{C}$ and $301{ }^{\circ} \mathrm{C}$ respectively. Generally, the combination of two mixers (LSM) have good temperature distribution for both upper edge as well as lower edge, which is beneficial for catalyst reaction performance and also very suitable to prevent the deposit formation.

The axial wall temperature distribution from the mixer downstream to the catalyst inlet (blue arrow in Figure 1) as represented in Figure 13. Wall temperature distributions of LM and SM at the catalyst inlet were $289^{\circ} \mathrm{C}$ and $294^{\circ} \mathrm{C}$, respectively, but the combination of two mixers (LSM) was $300^{\circ} \mathrm{C}$ due to better heat transfer effect. A continuous decrease in the temperature was observed from 0.3 to $0.5 \mathrm{~m}$ distance; with minimal temperature of $270{ }^{\circ} \mathrm{C}$ in SM. Low temperature region produces direct effect on the wall of pipe and reaction performance, without creates disturbance for the mixer.

Generally, temperature plays an important role in the reaction performance and deposit formation. With the use of LSM, the temperature remains above $280^{\circ} \mathrm{C}$ in axial and radial directions, which is very helpful for preventing the unwanted reactions and deposit formations.

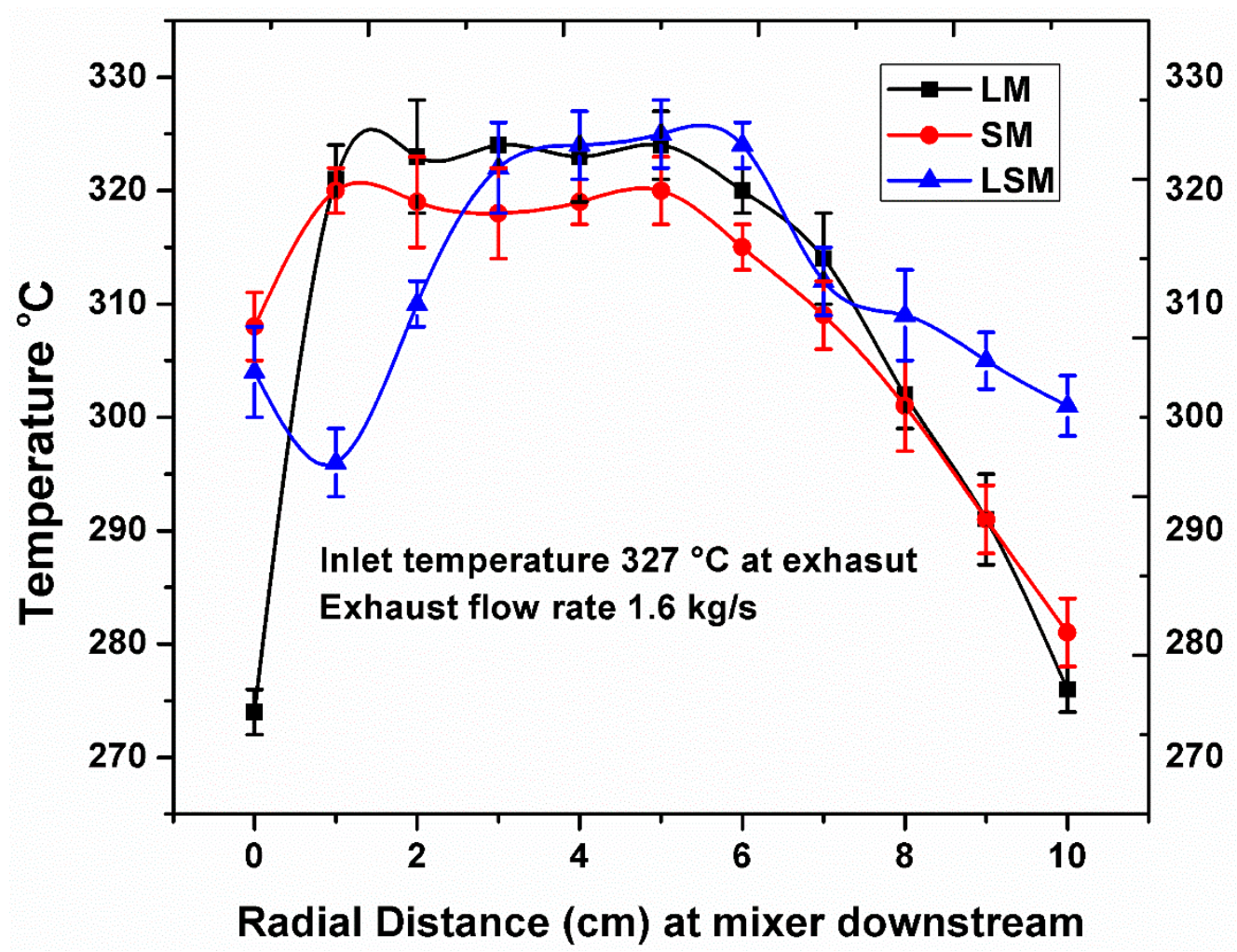

Figure 12. Radial distribution of temperature in the mixer downstream. 


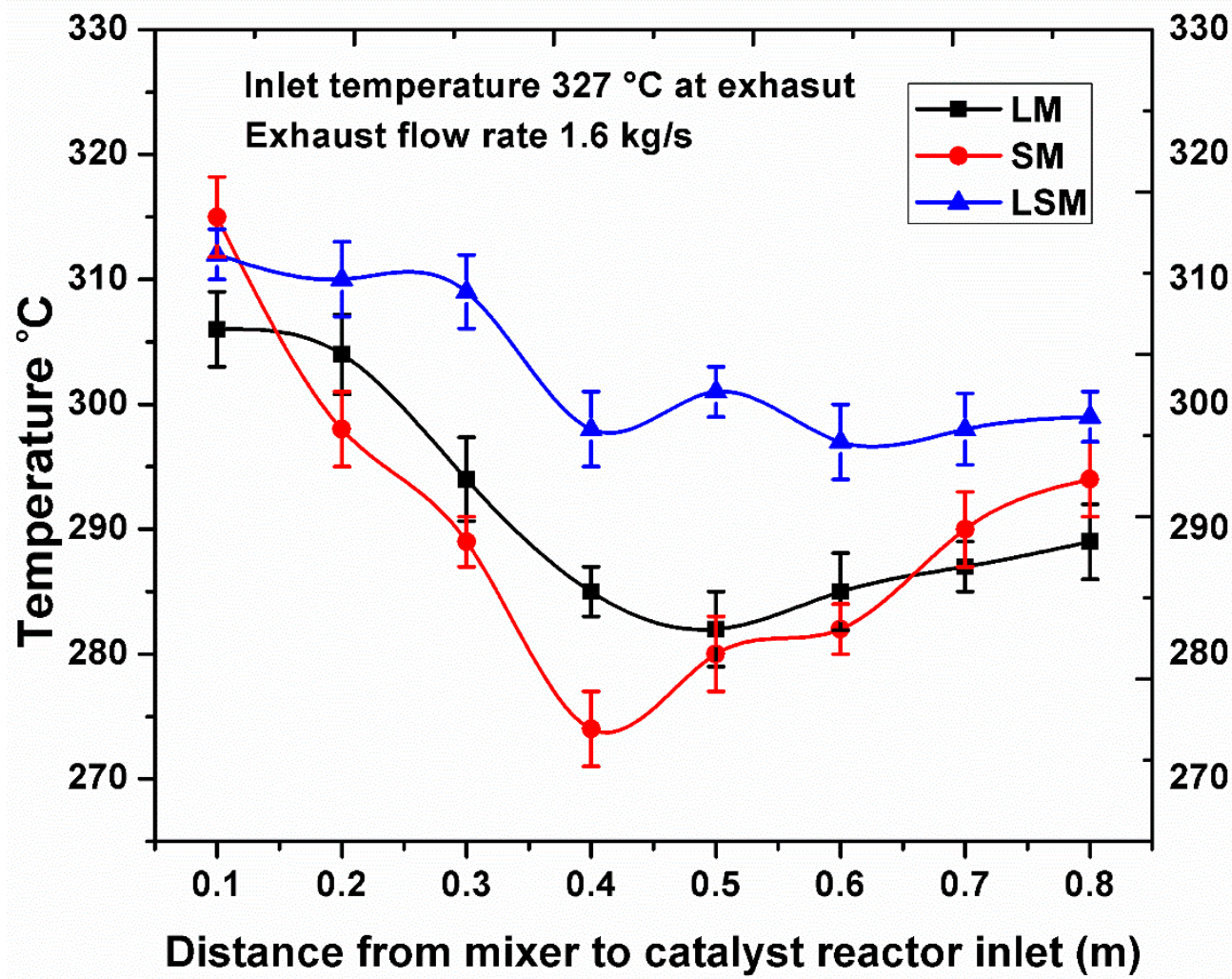

Figure 13. Axial distribution of temperature from mixer downstream to catalyst inlet in pipe wall.

\subsection{Working Performance of LSM-Based SCR System}

The standard ISO 8178 is the international marine Diesel engine test cycle used to measure the exhaust emissions from ships. By following the control requirements of exhaust emission as per IMO Tier III, standard marine Diesel engine test cycle has been divided into two parts one is ISO 8178 D2 test cycle for marine Diesel engine operated with constant speed and other is ISO 8178 E3 test cycle with propelling character for marine Diesel engine. In this study marine Diesel engine with propelling character was studied. Hence, the ISO 8178 E3 test cycle was used to measure the exhaust emissions. The weightage average value of $\mathrm{NO}_{\mathrm{x}}$ exhaust emission was calculated by ISO 8178 marine Diesel engine test cycle E3 as shown in Table 4 [30].

Table 4. ISO 8178 marine Diesel engine test cycle E3.

\begin{tabular}{ccccc}
\hline Type ISO 8178 E3 Mode & $\mathbf{1}$ & $\mathbf{2}$ & $\mathbf{3}$ & $\mathbf{4}$ \\
\hline Load (\%) & 25 & 50 & 75 & 100 \\
Speed $(\%)$ & 63 & 80 & 91 & 100 \\
Weightage factor & 0.15 & 0.15 & 0.5 & 0.2 \\
\hline
\end{tabular}

The overall weighted $\mathrm{NO}_{\mathrm{x}}$ exhaust emission level in $\mathrm{g} / \mathrm{kWh}$ can be calculated using Equation (16) [47].

$$
E F_{x}=\frac{\sum_{i=1}^{n} m_{i} W F_{i}}{\sum_{i=1}^{n} p_{i} W F_{i}}
$$

The main purpose of SCR system is to decrease the $\mathrm{NO}_{\mathrm{x}}$ emissions and to prevent the ammonia leakages responsible for air pollution. Figure 14 represents the $\mathrm{NO}_{\mathrm{x}}$ removal efficiency under different loading conditions. It was observed that, there is a small difference in between theoretical value (standard) and calculated value (simulation). At low load, the $\mathrm{NO}_{\mathrm{x}}$ removal efficiency is low, because 
under lower loading conditions, the exhaust temperature of Diesel engine is comparatively low, which directly affects the catalyst performance; as a result, the catalyst efficiency decreases. Figure 15 shows the $\mathrm{NH}_{3}$ escaping rate at different engine loading conditions. The rate of $\mathrm{NH}_{3}$ escaping decreases with the increase of engine load. $\mathrm{NH}_{3}$ escaping rate is relatively high at low load due to lower temperature of the exhaust gas, resulting in incomplete catalyst reaction. The reaction of $\mathrm{NH}_{3}$ oxidization is neglected for design of SCR model parameters in this study; therefore, more $\mathrm{NH}_{3}$ slipping occurs at low loading conditions. However, at higher loading conditions ( $75 \%$ and $100 \%)$, the $\mathrm{NH}_{3}$ escaping rate is less than $10 \mathrm{ppm}$, which meets the design requirement of the SCR system.

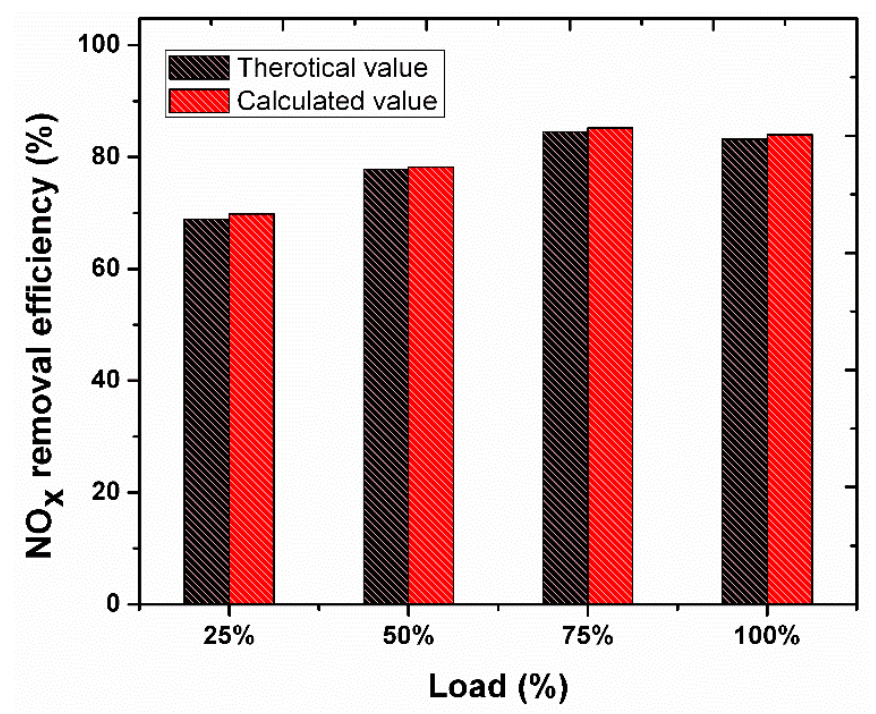

Figure 14. $\mathrm{NO}_{\mathrm{x}}$ removal efficiency under different engine loading conditions.

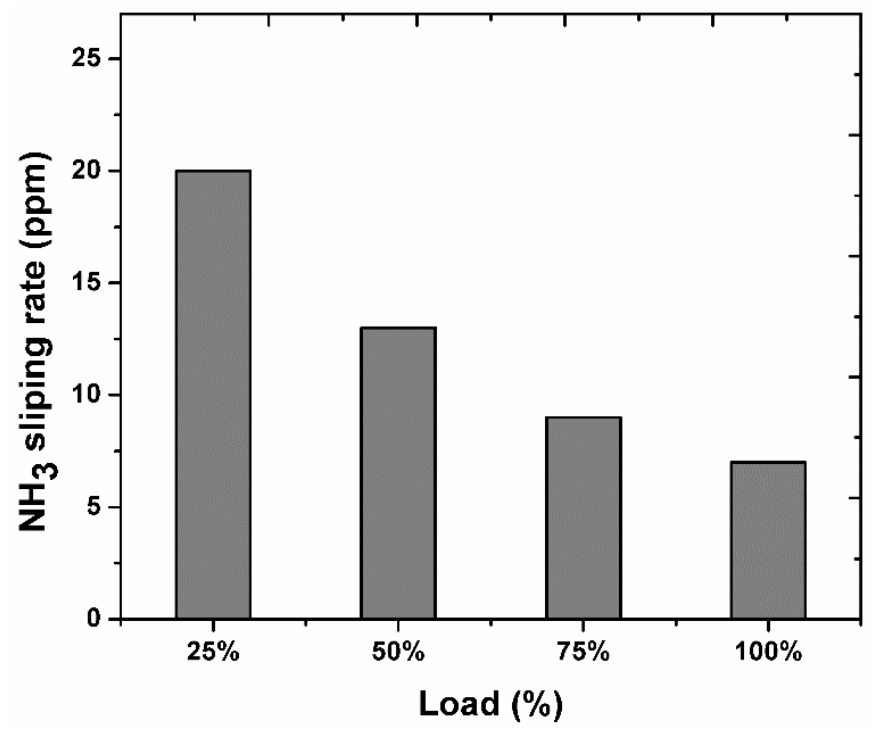

Figure 15. $\mathrm{NH}_{3}$ escaping rate under different engine loading conditions.

Verification of simulated results was confirmed by using ISO 8178 standard marine Diesel engine test cycle E3. According to emission regulations of IMO Tier III, the value of $\mathrm{NO}_{\mathrm{x}}$ emission should be less than $3.4 \mathrm{~g} / \mathrm{kWh}$ under all loading conditions. Figure 16 shows a $\mathrm{NO}_{\mathrm{x}}$ emission value of the LSM-based SCR system at different loading conditions. It was observed that $\mathrm{NO}_{\mathrm{x}}$ emission decreases as the load increases. The average weighted value of $\mathrm{NO}_{\mathrm{x}}$ emission was $2.44 \mathrm{~g} / \mathrm{kWh}$ for four different loads at the downstream of SCR catalyst. Hence, the system based on using LSM strongly meets the standard of IMO Tier III $\mathrm{NO}_{x}$ emission regulations effectively. 


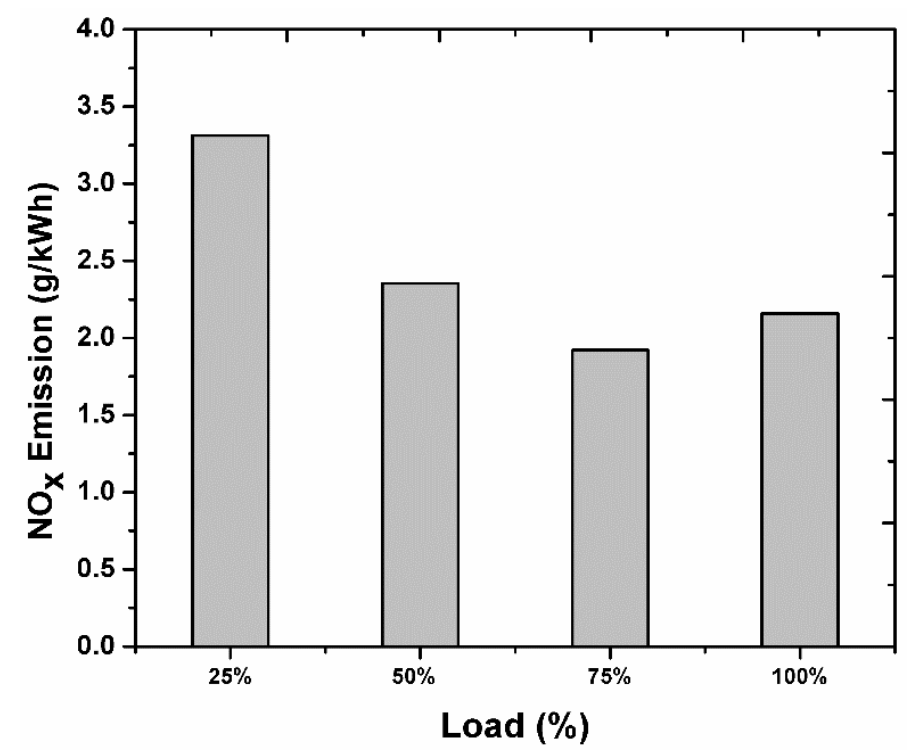

Figure 16. $\mathrm{NO}_{\mathrm{x}}$ emission under different engine loading conditions.

\section{Conclusions}

In this work, numerical methods were used to analyze the mixing performance, effects of mixers on the evaporation rate of urea, residence time of urea droplet in the pipe, and temperature distribution for the catalyst reaction and deposit formation. The prime results are shown below.

- For the in-line type mixer (LM), the uniformity index of velocity was good (0.93) but the uniformity of ammonia was poor (0.87). In contrary to LM, the swirl type mixer (SM) has good ammonia uniformity (0.94) but poor uniformity index of velocity (0.86). However, better values were observed by using combination of two mixers (LSM). The uniformity index of velocity and ammonia uniformity achieved the values of 0.95 and 0.96 , respectively, for LSM-based SCR system.

- The residence time UWS was studied. The results show that the residence time of urea droplets for LSM-based SCR system was $0.064 \mathrm{~s}$, which represents $47 \%$ and $29 \%$ decreases compared to LM and SM, respectively. Furthermore, the conversion of urea into ammonia is highly related with the residence time of urea droplets in the pipe. Hence, urea conversion achieves the value of $95.4 \%$ by using LSM, which is $19.3 \%$ and $12.2 \%$ higher than the value of LM and SM, respectively.

- It was also observed that the combination of two mixers (LSM) have good temperature distribution than the LM and SM for radial and axial directions, the temperature at catalyst inlet in axial direction was $300{ }^{\circ} \mathrm{C}$ for LSM-based SCR system which is suitable for the catalyst reaction performance and prevents the deposit formation.

- Finally, the simulated results of the model parameters were compared and verified by using ISO 8178 standard marine Diesel engine test cycle E3. The average weighted value of $\mathrm{NO}_{\mathrm{x}}$ emission was calculated as $2.44 \mathrm{~g} / \mathrm{kWh}$ for four different loads. Hence, it is concluded that the system based on using LSM strongly meets the standard of IMO Tier III $\mathrm{NO}_{\mathrm{x}}$ emission regulations effectively.

Author Contributions: Conceptualization, Methodology, Software, Data Curation, Writing-Original Draft Preparation and Validation, G.M. and S.Z.; Formal Analysis and Investigation Y.Z.; Supervision, Funding Acquisition, and Project Administration S.Z.; Writing-Review and Editing, A.H.S. and K.C.

Funding: We gratefully acknowledge the financial support of the National Key and Research and Development Program of China (No: 2016YFCO205400) and the provincial funding of the National Projects of Heilongjiang Province in China (No: GX17A020).

Conflicts of Interest: The authors declare no conflict of interest. 


\section{Abbreviations}

$\begin{array}{ll}\text { CFD } & \text { Computational Fluid Dynamics } \\ \text { ECA } & \text { Emission Control Areas } \\ \text { IMO } & \text { International Maritime Organization } \\ \text { LM } & \text { Line Mixer } \\ \text { LSM } & \text { Line Swirl Mixer } \\ \text { SM } & \text { Swirl Mixer } \\ \text { SCR } & \text { Selective Catalyst Reduction } \\ \text { UWS } & \text { Urea Water Solution }\end{array}$

\section{Nomenclature}

Symbol Name (Unit)

$\mathrm{R} \quad$ Gas constant $\left(\mathrm{J} \mathrm{kg}^{-1} \mathrm{~K}^{-1}\right)$

$\mathrm{P} \quad$ Pressure $(\mathrm{Pa})$

$\mathrm{T} \quad$ Reaction Temperature (K)

U Fluid velocity $(\mathrm{m} / \mathrm{s})$

P Droplet density $\left(\mathrm{m}^{2} / \mathrm{s}^{3}\right)$

K Turbulent kinetic energy $\left(\mathrm{m}^{2} / \mathrm{s}^{2}\right)$

$V_{t} \quad$ Velocity with time $(\mathrm{m} / \mathrm{s})$

$C_{\mu} \quad$ Closure coefficient

$C_{S} \quad$ Volume concentration $\left(\mathrm{m}^{3}\right)$

$\overrightarrow{j_{i}} \quad$ Diffusion flux

$D_{S} \quad$ Component diffusion coefficient

$S_{m} \quad$ Chemical reaction component mass

$\vec{V} \quad$ Gas velocity vector

$\mathrm{R}_{\mathrm{i}} \quad$ Net production rate of species

$S_{i} \quad$ Rate of creation from dispersed phase to user defined phase

$\mathrm{Y}_{\mathrm{i}} \quad$ Species destruction molar rate

$D_{T} \quad$ Turbulent diffusivity $\left(\mathrm{m}^{2} / \mathrm{s}\right)$

$D_{T, i} \quad$ Thermal diffusion coefficient $\left(\mathrm{m}^{2} / \mathrm{s}\right)$

$D_{T, m} \quad$ Mass diffusion coefficient

$C_{\text {water }} \quad$ Molar concentration of water

$K_{c} \quad$ Mass transfer coefficient $(\mathrm{m} / \mathrm{s})$

$T_{p} \quad$ Droplet temperature

$R_{i, r} \quad$ Species destruction molar rate

$m_{p} \quad$ Droplet mass $(\mathrm{kg})$

$u_{p} \quad$ Velocity of liquid droplet

$\rho_{p} \quad$ Density of liquid droplet

$F \quad$ Force except drag force

$C_{P} \quad$ Specific heat of liquid droplet $(\mathrm{J} / \mathrm{K})$

$A_{P} \quad$ Droplet surface area $\left(\mathrm{m}_{2}\right)$

$T \infty \quad$ Droplet environment temperature

$h \quad$ Convective heat transfer coefficient $\left(\mathrm{W} /\left(\mathrm{m}^{2} \mathrm{~K}\right)\right)$

$h_{f g} \quad$ latent heat of vaporization $(\mathrm{KJ} / \mathrm{kg})$

$V_{i} \quad$ Carrier Nominal velocity $(\mathrm{m} / \mathrm{s})$

$V_{\text {mean }} \quad$ Average velocity $(\mathrm{m} / \mathrm{s})$

$A_{i} \quad$ Cell area $\left(\mathrm{m}^{2}\right)$

A Sectional area of the plane $\left(\mathrm{m}^{2}\right)$

$E F_{x} \quad$ Weighted emission level $(\mathrm{g} / \mathrm{kWh})$

$m_{i} \quad$ Mass emission rate $(\mathrm{g} / \mathrm{h})$

$W F_{i} \quad$ Weighting factor

$P_{i} \quad$ Engine load

Ar Pre-exponential factor

Ea Activation energy $(\mathrm{J} / \mathrm{kmol})$

MW Species molecular weight 


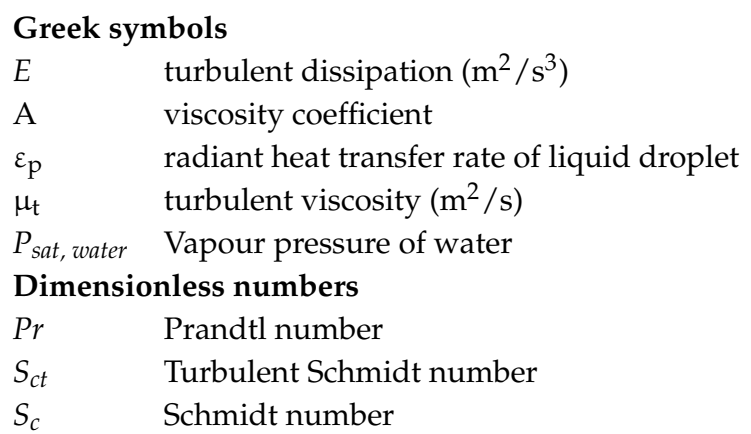

\section{References}

1. Zhanga, C.; Suna, C.; Wua, M.; Lub, K. Optimisation design of SCR mixer for improving deposit performance at low temperatures. Fuel 2019, 237, 465-474. [CrossRef]

2. Chen, W.; Fali, H.; Qin, L.; Jun, H.; Zhao, B.; Yangzhe, T.; Fei, Y. Mechanism and Performance of the SCR of NO with NH3 over Sulfated Sintered Ore Catalyst. Catalysts 2019, 9, 90. [CrossRef]

3. Hu, N.; Zhou, P.; Yang, J. Reducing emissions by optimising the fuel injector match with the combustion chamber geometry for a marine medium-speed diesel engine. Transp. Res. Part D Transp. Environ. 2017, 53, 1-16. [CrossRef]

4. International Maritime Organization. Annex VI of MARPOL 73/78, Regulations for the Prevention of 418 Air Pollution from Ships and NOx Technical Code; International Maritime Organization: London, UK, 2008; pp. 15-19.

5. Yewen, G.; Stein, W.W. A potentially overestimated compliance method for the Emission Control Areas. Transp. Res. Part D 2017, 55, 51-66.

6. Zamboni, G.; Moggia, S.; Capobianco, M. Hybrid EGR and turbocharging systems control for low $\mathrm{NO}_{\mathrm{x}}$, and fuel consumption in an automotive diesel engine. Appl. Energy 2016, 165, 839-848. [CrossRef]

7. Nova, I.; Tronconi, E. Urea-SCR Technology for deNO $x$ after Treatment of Diesel Exhausts; Springer: New York, NY, USA, 2014; pp. 12-18.

8. Koebel, M.; Elsener, M.; Madia, G. Reaction pathways in the selective catalytic reduction process with NO and $\mathrm{NO}_{2}$ at low temperatures. Ind. Eng. Chem. Res. 2001, 40, 52-59. [CrossRef]

9. Sadashiva, P.S. Review on Selective Catalytic Reduction (SCR)-A Promising Technology to mitigate $\mathrm{NO}_{\mathrm{x}}$ of Modern Automobiles. Int. J. Appl. Eng. Res. 2018, 13, 5-9.

10. Shahariarm, G.M.H.; Lim, O.T. A Study on Urea-Water Solution Spray-Wall Impingement Process and Solid Deposit Formation in Urea-SCR de-NOx System. Energies 2018, 12, 125. [CrossRef]

11. Koebel, M.; Elsener, M.; Kleemann, M. Urea-SCR: A promising technique to reduce $\mathrm{NO}_{x}$ emissions from automotive diesel engines. Catal. Today 2000, 59, 335-345. [CrossRef]

12. Fang, H.L.; DaCosta, H.F.M. Urea thermolysis and NOx reduction with and without SCR catalysts. Appl. Catal. B Environ. 2003, 46, 14-34. [CrossRef]

13. Jeong, S.J.; Sang, J.L.; Kim, W.S. Numerical Study on the Optimum Injection of Urea-Water Solution for

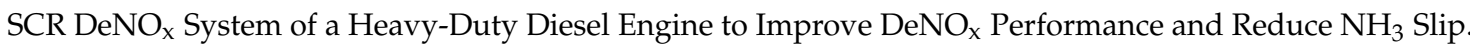
Environ. Eng. Sci. 2008, 25, 1017-1036. [CrossRef]

14. Varna, A.; Spiteri, A.C.; Wright, Y.M. Experimental and numerical assessment of impingement and mixing of urea-water sprays for nitric oxide reduction in diesel exhaust. Appl. Energy 2015, 157, 824-837. [CrossRef]

15. Grout, S.; Blaisot, J.B.; Pajot, K. Experimental investigation on the injection of an urea-watersolution in hot air stream for the SCR application: Evaporation and spray/wall interaction. Fuel 2013, 106, 166-177. [CrossRef]

16. Choi, C.; Sung, Y.; Choi, G.M.; Kim, D.J. Numerical Analysis of Urea Decomposition with Static Mixers in Marine SCR System. J. Clean Energy Technol. 2015, 3, 39-42. [CrossRef]

17. Haitao, D.; Dawei, M.; Renbin, Z.; Bowen, S.; Jun, H. Impact of Control Measures on Nitrogen Oxides, Sulfur Dioxide and Particulate Matter Emissions from Coal-Fired Power Plants in Anhui Province, China. Atmosphere 2019, 10, 35. 
18. Tana, L.; Fenga, P.; Yangb, S.; Guoa, Y.; Liua, S.Z.L. CFD studies on effects of SCR mixers on the performance of urea conversion and mixing of the reducing agent. Chem. Eng. Process. Process Intensif. 2018, 123, 82-88. [CrossRef]

19. Birkhold, F.; Meingast, U.; Wassermann, P. Modeling and simulation of the injection of urea-water-solution for automotive SCR DeNOx-systems. Appl. Catal. B Environ. 2007, 70, 119-127. [CrossRef]

20. Ström, H.; Lundström, A.; Andersson, B. Choice of urea-spray models in CFD simulations of urea-SCR systems. Chem. Eng. J. 2009, 150, 69-82. [CrossRef]

21. Rajadurai, S. Improved NOx Reduction Using Wiremesh Thermolysis Mixer in Urea SCR System; SAE Technical Paper 2008; SAE: Zürich, Switzerland, 2008.

22. Zhang, X.; Romzek, M.; Morgan, C. 3-D Numerical Study of Mixing Characteristics of $\mathrm{NH}_{3}$ in Front of SCR; SAE Technical Paper; SAE: Zürich, Switzerland, 2006.

23. Chen, M.; Williams, S. Modeling and Optimization of SCR-Exhaust Aftertreatment Systems; SAE, World Congress and Exhibition; SAE: Zürich, Switzerland, 2005.

24. Capetillo, A.; Ibarra, F. Multiphase injector modeling for automotive SCR systems: A full factorial design of experiment and optimization. Comput. Math. Appl. 2017, 74, 89-97. [CrossRef]

25. Park, T.; Kim, Y.S.; Lee, I.; Choi, G.; Kim, D. Effect of static mixer geometry on flow mixing and pressure drop in marine SCR applications. Int. J. Nav. Arch. Ocean Eng. 2014, 6, 27-38. [CrossRef]

26. Yuanqing, Z.; Zhang, R.; Zhou, S.; Huang, C.; Feng, Y.; Shreka, M.; Zhang, C. Performance Optimization of High-Pressure SCR System in a Marine Diesel Engine. Part I: Flow Optimization and Analysis. Top. Catal. 2019. [CrossRef]

27. Olivier, F.; Toshiyuki, Y. Development of Static Mixer Device for Heavy Duty Diesel Engine SCR After-treatment System. Calsonic Kansei Tech. Rev. 2012, 9, 50-55.

28. Hyman, D. Mixing and agitation. Adv. Chem. Eng. 1999, 3, 119-202.

29. Kuhnke, D. Spray Wall Interaction Modeling by Dimensionless Data Analysis. Ph.D. Thesis, Universitat Darmstadt, Darmstadt, Germany, 2004.

30. Emission Test Cycles. Available online: www.dieselnet.com/standards/cycles/iso8178.php (accessed on 20 December 2018).

31. Yong, Y. Development of a 3D Numerical Model for Predicting Spray, Urea Decomposition and Mixing in SCR Systems; SAE Technical Papers; SAE: Zürich, Switzerland, 2007.

32. Jeong, S.; Lee, S.; Kim, W.; Lee, C. Simulation on the Optimum Shape and Location of Urea Injector for Urea-SCR System of Heavy-Duty Diesel Engine to Prevent NH3 Slip; SAE Technical Paper; SAE: Zürich, Switzerland, 2005.

33. Yakhot, V.; Orszag, S.; Thangam, S.; Gatski, T.; Speziale, C. Development of turbulence models for shear flows by a double expansion technique. Phys. Fluids A 1992, 4, 1510-1520. [CrossRef]

34. Andersson, B.; Andersson, R.; Håkansson, L. Computational Fluid Dynamics for Engineers; Cambridge University Press: Cambridge, UK, 2011; pp. 56-66.

35. Wang, H.; Fischman, G.S. Role of liquid droplet surface diffusionin the vapor-liquidsolid whisker growth mechanism. J. Appl. Phys. 1994, 76, 1557-1562. [CrossRef]

36. Berlemont, A.; Grancher, M.S.; Gouesbet, G. Heat and mass transfer coupling between vaporizing droplets and turbulence using a Lagrangian approach. Int. J. Heat Mass Transf. 1995, 38, 3023-3034. [CrossRef]

37. Schaber, P.M.; Colson, J.; Higgins, S. Study of the urea thermal decomposition (pyrolysis) reaction and importance to cyanuric acid producition. Am. Lab 1999, 31, 13-21.

38. Schaber, P.M.; Colson, J.; Higgins, S. Thermal decomposition (pyrolysis) of urea in an open reaction vessel. Thermochim. Acta 2004, 424, 131-142. [CrossRef]

39. Law, C.K. Recent advances in droplet vaporization and combustion. Prog. Energy Combust. Sci. 1982, 8, 171-201. [CrossRef]

40. Spiteri, A.; Eggenschwiler, P.D.; Liao, Y.; Wigley, G.; Michalow-Mauke, K.A.; Elsener, M. Comparative analysis on the performance of pressure and air assisted urea injection for selective catalytic reduction of $\mathrm{NO}_{\mathrm{x}}$. Fuel 2015, 161, 269-277. [CrossRef]

41. Shahariar, G.M.H.; Lim, O.T. Investigation of urea-water solution spray impingement on the hot surface of automotive SCR system. J. Mech. Sci. Technol. 2018, 32, 2935-2946. [CrossRef]

42. $\mathrm{Xu}, \mathrm{Z}$; $\mathrm{Liu}, \mathrm{J} . ; \mathrm{Fu}, \mathrm{J}$. Experimental investigation on the urea injection and mixing module for improving the performance of Urea-SCR in diesel engines. Can. J. Chem. Eng. 2018, 96, 1417-1429. [CrossRef] 
43. Paramadayalan, T.; Pant, A. Selective catalytic reduction converter design: The effect of ammonia nonuniformity at inlet. Korean J. Chem. Eng. 2013, 30, 2170-2177. [CrossRef]

44. Fischer, S.; Fischer, R.B.; Lauer, T. Impact of the turbulence model and numerical approach on the prediction of the ammonia homogenization in an automotive SCR system. SAE Int. J. Eng. 2012, 5, 1443-1458. [CrossRef]

45. Rourke, P.J.O.; Amsden, A.A. A Spray/Wall Interaction Submodel for the KIVA-3 Wall Flm Model; SAE Technical Paper; SAE: Zürich, Switzerland, 2000.

46. Marin, P.; Fissore, D.; Barresi, A.A. Simulation of an industrial-scale process for the SCR of $\mathrm{NO}_{\mathrm{x}}$ based on the loop reactor concept. Chemical Eng. Process. Process Intensif. 2009, 48, 311-320. [CrossRef]

47. Gysel, N.R.; Robert, L.; Russell; Welch, W.A.; Cocker, I.D.R. Impact of Aftertreatment Technologies on the In-Use Gaseous and Particulate Matter Emissions from a Tugboat. Energy Fuels 2016, 30, 684-689. [CrossRef]

2019 by the authors. Licensee MDPI, Basel, Switzerland. This article is an open access article distributed under the terms and conditions of the Creative Commons Attribution (CC BY) license (http:// creativecommons.org/licenses/by/4.0/). 